\title{
Investigation of the influence of the forming process and finishing processes on the properties of the surface and subsurface of hybrid components
}

\author{
Laura Budde $^{1}$. Vannila Prasanthan ${ }^{2}$. Jens Kruse ${ }^{3} \cdot$ Mohamad Yusuf Faqiri $^{4}$. Marius Lammers ${ }^{1}$. Jörg Hermsdorf ${ }^{1}$. \\ Malte Stonis $^{3}$. Thomas Hassel ${ }^{4}$ - Bernd Breidenstein ${ }^{2}$. Bernd-Arno Behrens ${ }^{3}$ - Berend Denkena ${ }^{2}$. \\ Ludger Overmeyer ${ }^{1}$
}

Received: 31 May 2021 / Accepted: 13 September 2021 / Published online: 25 October 2021

(C) The Author(s) 2021

\begin{abstract}
Due to the increased integration of functions, many components have to meet high and sometimes contradictory requirements. One way to solve this problem is Tailored Forming. Here, hybrid semi-finished products are manufactured by a joining or cladding process, which are then hot-formed and finished. For the design of hybrid components for a possible later industrial application, knowledge about properties of hybrid components is required. In this paper it is investigated how the respective process steps of the Tailored Forming process chain change the surface and subsurface properties of the applied cladding layer. For this purpose, shafts made of unalloyed steel are provided with a high-alloy austenitic steel X2CrNiMo1912 cladding by laser hot-wire cladding. Subsequently, hot forming is carried out by cross-wedge rolling and the finishing by turning and deep rolling. After each process step, the subsurface properties of the cladding such as microstructure, hardness and residual stress state are examined. Thus, the influence of different process steps on the subsurface properties in the process chain of manufacturing hybrid shafts can be analyzed. This knowledge is necessary for the specific adjustment of defined properties for a required application behavior.
\end{abstract}

Keywords Tailored forming $\cdot$ Residual stress $\cdot$ Laser hot-wire cladding $\cdot$ Deep rolling $\cdot$ Cross-wedge rolling . Hybrid components

\section{Introduction}

The use of hybrid components consisting of different materials has the advantage compared to mono-material components that locally adapted mechanical, chemical and physical properties of the component can be implemented.

Laura Budde

1.budde@1zh.de

1 Laser Zentrum Hannover e.V., Hollerithallee 8, 30419 Hannover, Germany

2 Leibniz Universität Hannover, Institute of Production Engineering and Machine Tools, An der Universität 2, 30823 Garbsen, Germany

3 IPH - Institut für Integrierte Produktion Hannover gGmbH, Hollerithallee 6, 30419 Hannover, Germany

4 Leibniz Universität Hannover, Institute of Materials Science, An der Universität 2, 30823 Garbsen, Germany
Increasing requirements for lightweight design, miniaturization and function integration can therefore be met more easily. A common method for the protection of stress exposed component areas is the application of a protective cladding. Depending on the chosen material of the cladding, protection of the base material against abrasive wear, mechanical stress and chemical influences such as corrosion can be achieved. This enables a resource-saving material selection such as the combination of a low-alloy structural steel with a higher-strength steel or a corrosion-resistant stainless steel. After the protective cladding has been applied, machining is carried out to achieve dimensional and shape accuracy. However, the weld microstructure generated by the heat input of the cladding process is not suitable for all mechanically highly stressed components. Blohm et al. have shown that a subsequent hot forming process can be used to transform the weld structure into a fine-grained structure with better mechanical properties than the initial weld microstructure through complete austenitization followed 
by microstructure formation. The residual stresses caused by the heat input of the welding process are neutralized [1]. It is well known, and has been proven a lot of times, that the surface and subsurface properties have a considerable influence on the functional surface properties and thus on the functional performance of highly loaded parts [2]. The machining process, as the final step in the process chain, can influence the ultimate surface and subsurface properties of a part favorably, as well as detrimentally. Against this background, it is necessary to consider the change in surface and subsurface properties within the process chain in order to investigate the possibilities of modifying this.

\subsection{Tailored Forming}

The combination of a deposition welding process with a subsequent hot forming process followed by a combination of machining, heat treatment and finishing is called a Tailored Forming process chain. In this process chain, semifinished parts that are advantageous to clad are provided with claddings and then hot formed with a near netshaped contour. Subsequently, machining and optionally heat treatment is carried out. The Tailored Forming process chain is shown in Fig. 1. This principle can be used for various material combinations and components.

Behrens et al. and Chugreeva et al. manufactured hybrid bevel gears using a Tailored Forming process chain [3, 4]. Shafts of low alloyed steel C22.8 with a protective cladding of heat treatable steel $41 \mathrm{Cr} 4$ were manufactured using a plasma transferred arc (PTA) welding process. A cladding of martensitic $\mathrm{Cr}-\mathrm{Si}$ alloyed valve steel $\mathrm{X} 45 \mathrm{CrSi} 9-3$ was applied onto shafts of $\mathrm{C} 22.8$ using laser hot-wire cladding (LHWC). Hot forming and a process integrated heat treatment led to high hardness values of $600 \mathrm{HV} 0.5$ in the tooth tip and $750 \mathrm{HV} 0.5$ in the tooth root for the material combination $\mathrm{X} 45 \mathrm{CrSi}-3$ and $\mathrm{C} 22.8$ and a lower hardness of $150 \mathrm{HV} 0.5$ in the base material. Coors et al. Pape et al. and Behrens et al. used the Tailored Forming process chain to produce hybrid thrust bearing washers made of S235JR or C22.8 with a protective cladding of $41 \mathrm{Cr} 4$ (PTA), X45CrSi9-3 (LHWC) and 100Cr6 (PTA) for the running surface [5-7]. The hybrid components were forged, machined, heat treated and tested. In all cases, the hot forming process led to recrystallization and a fine-grained microstructure. The hybrid bearing washers with $41 \mathrm{Cr} 4$ and $\mathrm{X} 45 \mathrm{CrSi} 9-3$ cladding achieved $70-85 \%$ of the service life of conventional bearing washers made of bearing steel $100 \mathrm{Cr} 6$. A service life of $82 \%$ was achieved by the hybrid bearing washers with $100 \mathrm{Cr} 6$ cladding. The failure was interpreted as premature due to small pores below the surface in the cladding area.

Up to now, the focus of investigations on the Tailored Forming process chain has been on high-strength cladding materials for contact surfaces. In this paper, the applicability of $\mathrm{X} 2 \mathrm{CrNiMo19-12}$ as a cladding material for the Tailored Forming process chain is investigated. This steel is frequently used to create corrosion-resistant claddings and has lower hardness and higher thermal expansion coefficients than the previously mentioned materials used for Tailored Forming. In addition to its use as corrosion protection, it is possible to use the cladding material $\mathrm{X} 2 \mathrm{CrNiMo19-12}$ as an intermediate layer in combination with a high-strength cladding such as $\mathrm{X} 45 \mathrm{CrSi} 9-3$. The high coefficient of thermal expansion of the intermediate layer compared to base material and high-strength cladding could be used in such a hybrid multimaterial cladding system to form compressive residual stresses in the high-strength cladding after hot forming, which increases the service life of the workpiece. A shaft with bearing seat is used as the target geometry for the investigations, although the strength of the austenitic material is unsuitable for such an application. The necessary forming tools are available for this geometry and have already been tested through studies on Tailored Forming of hybrid shafts with high-strength claddings. A later application of the hybrid multi-material system in this application is possible.

The hybrid design of high-performance components opens up new potentials in terms of lightweight design or a more requirement-oriented design. However, there is no knowledge about the change of surface and subsurface properties within the process chain for the cladding material $\mathrm{X} 2 \mathrm{CrNiMo19-12.} \mathrm{If} \mathrm{this} \mathrm{knowledge} \mathrm{is} \mathrm{available,} \mathrm{a} \mathrm{desired}$

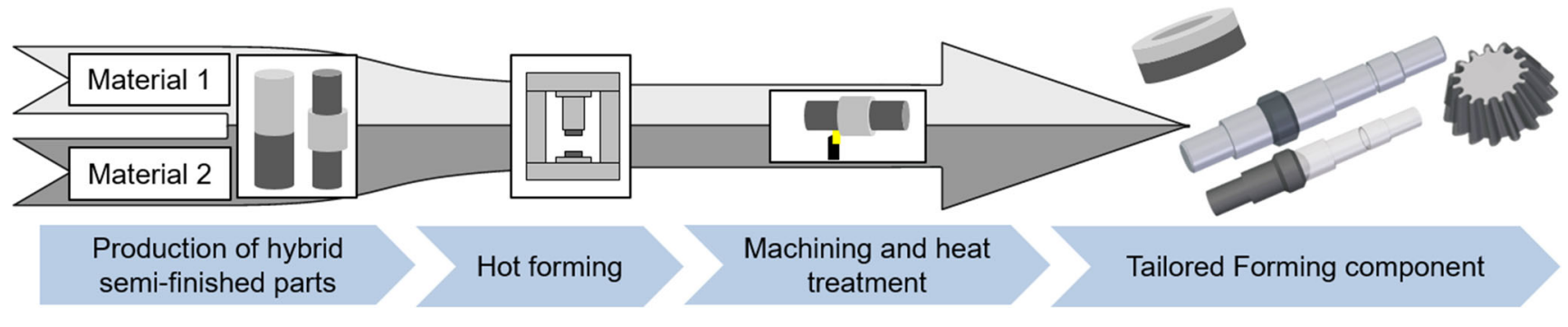

Fig. 1 Tailored Forming process chain 
or required final state of a component can be manufactured in a controlled manner. Research questions that need to be addressed are as follows:

1. How and why do the following surface and subsurface properties change within the process chain?
(a) Hardness
(b) Microstructure
(c) Residual stress state
(d) Surface roughness
(e) Cladding layer distribution

2. Is it possible to carry out a cross-wedge rolling process with hybrid components of this material combination?

\subsection{Deposition welding}

Various processes are known for the application of corrosion-resistant claddings in the thickness range from around $0.5 \mathrm{~mm}$ to several millimeters [8]. Khara et al. used a gas metal arc welding process to manufacture stainless steel layers on a low alloy steel plate [9]. The corrosion resistance was tested using a solution of ferric chloride with diluted hydrochloric acid and ethyl alcohol which was applied for $24 \mathrm{~h}$. The best corrosion resistance was found at a parameter combination with a low heat input during the cladding process. Barroi et al. investigated an arc-based deposition welding process with increased deposition rate called laserassisted double-wire non-transferred arc welding process $[10,11]$. In this process an arc is generated between two electrodes above the substrate. The molten material drops onto the component. A laser beam oscillating on the melt pool provides additional energy for the melt pool and ensures better bonding to the substrate. Deposition rates of $7.5 \mathrm{~kg} / \mathrm{h}$ of the material X2CrNiMo19-12 on S355JR have already been achieved with this process. A good corrosion protection of the substrate was given.

Another cladding process is laser metal deposition welding with wire (LMD-W). In this process, the cladding material is provided as a wire and a laser beam is used to melt the wire and ensure a metallurgical bond to the substrate. LMD-W offers the possibility of achieving high deposition rates of up to $5 \mathrm{~kg} / \mathrm{h}$ with almost complete utilization of the supplied material $[12,13]$. Barroi et al. used a stainless steel AISI 318L wire to investigate the influence of the laser power on the shape of single weld seams [14]. Shi et al. investigated a coaxial LMD-W process with stainless steel AISI 304 as cladding material [15]. A model for single seam geometry was established and a thin-walled part was successfully welded. In order to improve the energy efficiency of the process a conductive wire preheating can be used. Such a process is called laser hot-wire cladding or laser metal deposition welding with hot-wire. Preheating the wire reduces the required laser power and leads to less heat input into the substrate and less dilution [16]. Wen et al. used stainless steel ER410NiMo as cladding material in a hot wire laser deposition welding process to investigate weld seam geometry and overlap [17]. The cladding has been optimised in terms of dilution, defects and waviness. A parameter combination for a defectfree cladding with constant thickness was found. Pajukoski et al. used coaxial cold- and hot-wire laser cladding processes to investigate the corrosion resistance of $\mathrm{Ni}$ based Inconel 625 and Thermanit 2509 super stainless steel claddings on mild steel [18]. It has been demonstrated that Inconel 625 cladding with a low degree of dilution of less than $1 \%$ can pass a test with acetic salt spray according to ASTM G85 for $2000 \mathrm{~h}$ without showing signs of corrosion. Samples with a higher dilution showed varying degrees of corrosion, probably caused by a higher iron content. The average pitting temperature of the thermanit cladding was in the range of a wrought duplex stainless steel with similar composition.

\subsection{Hot forming via cross-wedge rolling}

Cross-wedge rolling (CWR) is a forming process which is often used for pre-forming. Depending on the forming wedge geometry and the number of the forming wedges used, cross-section reductions (dA) of more than $80 \%$ can be achieved. Usually, 55-70\% cross-section reduction per forming wedge insertion are recommended for better process stability. This ensures the avoidance of forming defects like internal cracking, necking or damaged surfaces of the workpiece. Therefore, if high amounts of dA are desired, multiple forming wedges, serially arranged, should be used $[19,20]$. The temperature of the work piece during cross-wedge rolling directly impacts the necessary forming forces [21]. Higher work piece temperatures decrease the forming forces and may also reduce the possibility of internal voids and cracks appearing [21-23]. Those internal cracks can influence the strength of the parts negatively [24]. The overall process window depends largely on the work piece material used and the amount of cross-section reduction applied and the corresponding geometry of the forming wedges [19]. Therefore, possible process windows can and should be determined via FE-Analysis first.

CWR, die forging and impact extrusion are the primarily investigated forming processes within the Tailored Forming process chain. Process parameters of the CWR forming operation can influence the quality of the parts produced within the Tailored Forming process chain. Forming temperatures, heating strategies, forming velocities and tool spacing can largely influence the quality of the rolled part and therefore impact the subsequent process chain operations $[20,25]$. Kruse et al. investigated 
the combination of a deposition welding process with $\mathrm{X} 45 \mathrm{CrSi} 9-3$ (LHWC) and 100Cr6 (PTA) as cladding material on a shaft of mild steel $\mathrm{C} 22.8$ with a subsequent CWR process. Hybrid products with different cladding geometries could be formed successfully [26].

Figure 2 shows the typical process of CWR that is investigated experimentally and via simulation within the Tailored Forming process chain.

\subsection{Turning and deep rolling}

The final process step in the production of hybrid components is machining. The machining process has a significant influence on the application behavior and service life of components by means of the surface and subsurface properties produced [2]. Component topography and roughness are influenced by the choice of the finishing process as well as the respective process parameters and tool geometry. Previous studies have shown that the feed rate has a significant influence on surface roughness during turning. Cutting speed and tool geometry determine the surface finish. It is generally assumed that an increase in cutting speed leads to a finer surface quality. However, investigations show that the effects are strongly materialdependent and can show opposite tendencies [27, 28]. The material-specific differences can be attributed to the material separation mechanisms and side effects, such as adhesions at the cutting edge [29]. The subsequent application behavior of hybrid components is influenced not only by the surface finish but in particular by the subsurface properties such as residual stresses, hardness or microstructure. These are primarily determined by the mechanical and thermal loads during the machining process.
Through finishing processes, such as deep rolling, the subsurface properties can be modified in a larger depth range [30]. While in turning the resulting residual stresses are mainly determined by the passive force, in deep rolling the residual stresses are defined by the Hertzian pressure of the rolling ball on the component surface. The material depth influenced by deep rolling is larger than the material depth influenced by turning. For example, the affected subsurface area due to hard turning of $100 \mathrm{Cr} 6$ is significantly smaller with maximum $200 \mu \mathrm{m}$ than with $500 \mu \mathrm{m}$ for deep rolling [31]. The reason for this is that during turning material is separated with less plastic deformation of the new surface while during deep rolling severe elastoplastic deformation takes place on the surface and the subsurface.

\section{Materials and methods}

In this paper, the process steps of deposition welding, crosswedge rolling, turning and deep rolling for the production of hybrid components are examined with regard to their influence on the applied cladding layer. The course of the investigations is shown in Fig. 3. A laser hot-wire cladding process is used to produce hybrid semi-finished products. Subsequently, CWR is used to produce hybrid shafts. In order to achieve the final dimensions of the shaft, machining is carried out. Finally, the surface is modified by deep rolling. After each process step, investigations of the surface and subsurface properties are carried out. Based on this, the influence of the processes on surface and subsurface properties is examined along the process chain. The knowledge gained from these investigations is

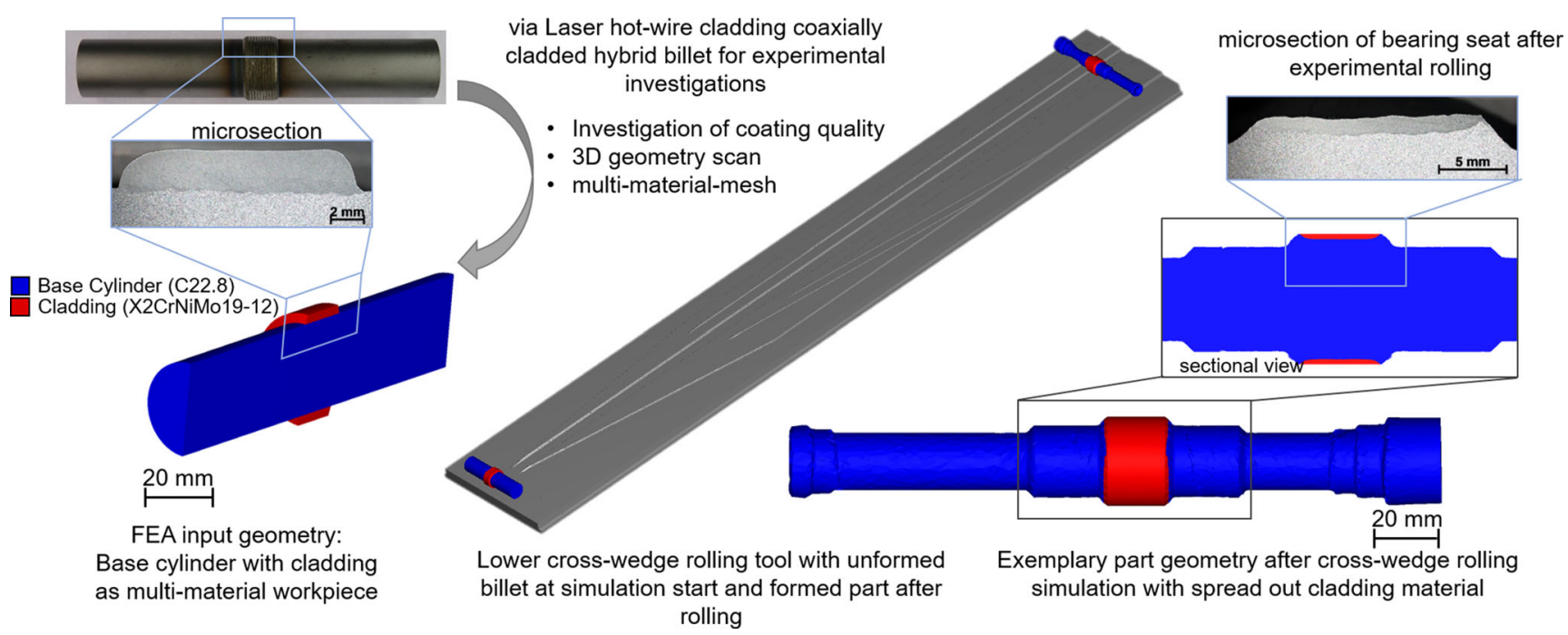

Fig. 2 Process overview of cross-wedge rolling of hybrid workpieces 
Fig. 3 Process chain and investigations

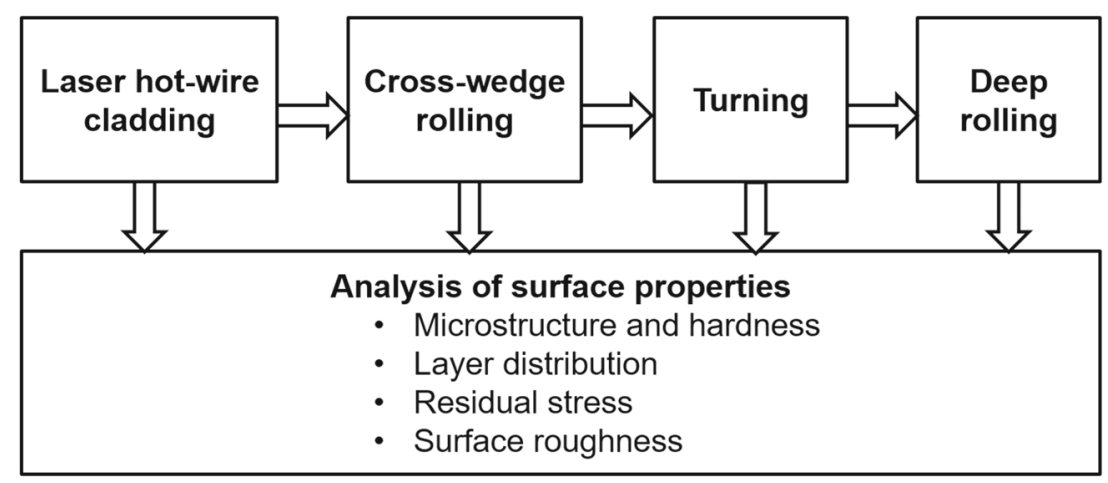

the basis for the design of multi-material cladding systems with specifically applied surface and subsurface properties like residual stresses.

\subsection{Materials}

The austenitic steel $\mathrm{X} 2 \mathrm{CrNiMo19}-12$ is used as cladding material for the investigation. The shafts consist of the unalloyed carbon steel C22.8. The chemical composition of the base material and the cladding material is shown in Table 1. While $\mathrm{C} 22.8$ has a coefficient of thermal expansion of $14.1 \cdot 10^{-6} \mathrm{~K}^{-1}$ in the temperature range from 20 to $400{ }^{\circ} \mathrm{C}$ [34], $\mathrm{X} 2 \mathrm{CrNiMo19-12}$ has a significantly higher coefficient of thermal expansion of $18 \cdot 10^{-6} \mathrm{~K}^{-1}$ in the temperature range from 20 to $500{ }^{\circ} \mathrm{C}$ [35]. It is assumed that this difference in the coefficients of thermal expansion leads to the formation of thermally induced residual stresses during cooling after cross-wedge rolling.

The cladding material has a tensile strength of 500$700 \mathrm{MPa}$ [35]. The tensile strength of the base material is slightly lower at 410-540 MPa [32].

\subsection{Laser hot-wire cladding}

The hybrid semi-finished products are manufactured by laser hot-wire cladding. For this purpose, the coaxial deposition welding head MK-II by Laser Zentrum Hannover e.V. is used. Here, the laser radiation supplied by a diode laser via fiber is first collimated and then focused with a focusing lens. Below the focusing lens is a pyramid with a square base. This pyramid divides the laser beam into four partial beams and deflects them outwards to a mirror, which deflects them and recombines the beams at the tip of the wire.
Due to the coaxial arrangement of wire and laser beams, the process is independent regarding the welding direction. This is advantageous compared to the lateral arrangement of the wire feed, especially during the production of complex components $[18,36]$. The LZH coaxial deposition welding head is shown in Fig. 4.

Base cylinders with a diameter of $27 \mathrm{~mm}$ and a length of $120 \mathrm{~mm}$ are used as substrate. The substrates were sandblasted and cleaned with ethanol before welding. Preheating was not used. For the production of the hybrid semi-finished products, the base cylinder is placed on a rotary axis that can be moved in the X-Y plane. By superimposing the rotational movement with the movement in the X-direction, spiral weld seams are applied to the substrate. The weld seams are welded centrally onto the base cylinder. The cladding consists of two layers, each with 9 adjacent seams with a seam-to-seam offset of $1.6 \mathrm{~mm}$, resulting in a cladding width of $14.4 \mathrm{~mm}$ and a total height of $1.4 \mathrm{~mm}$. A shaft with a cladding is shown in Fig. 5 .

An overview of the parameters used for laser hot-wire cladding of the austenitic stainless steel on the base material is given in Table 2. The stickout describes the distance from the wire nozzle to the workpiece.

\subsection{Cross-wedge rolling}

A CWR module (a self-built test stand at the IPH - Institut für Integrierte Produktion Hannover $\mathrm{gGmbH}$ ) is used for the experimental investigations (see Fig. 6). The CWR module consists of a steel machine frame in which two sleds can be moved translationally on plain bearings. Onto the sleds, the CWR tools are mounted within a tool frame. The horizontal movement of the sleds is generated by one hydraulic cylinder per sled. Each hydraulic cylinder can

Table 1 Chemical composition in wt.\% of C22.8 [32] and X2CrNiMo19-12 [33]

\begin{tabular}{|c|c|c|c|c|c|c|c|c|c|}
\hline & $\mathrm{Fe}$ & $\mathrm{C}$ & $\mathrm{Si}$ & Mn & $\mathrm{P}$ & S & $\mathrm{Cr}$ & $\mathrm{Ni}$ & Mo \\
\hline C22.8 (1.0460) & bal. & $0.18-0.23$ & $<0.40$ & $0.30-0.90$ & $<0.025$ & $<0.015$ & $<0.30$ & $<0.3$ & $<0.08$ \\
\hline X2CrNiMo19-12 (1.4430) & bal. & 0.013 & 0.873 & 1.709 & 0.017 & 0.01 & 18.3 & 12.22 & 2.641 \\
\hline
\end{tabular}




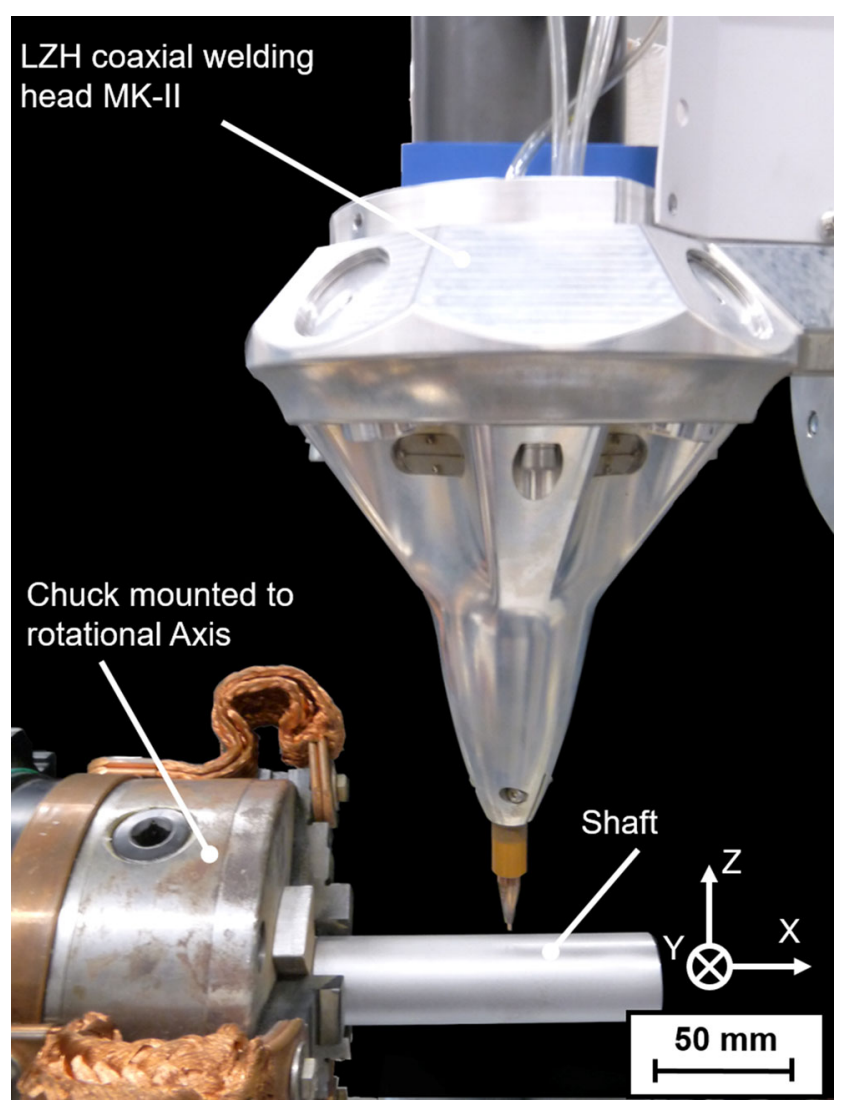

Fig. 4 Experimental setup for coaxial LHWC

apply up to $125 \mathrm{kN}$ of force. The vertical force required to ensure a constant distance between the dies, regardless of the forming forces, is generated by a hydraulic press DZP 630 manufactured by Walter NEFF GmbH Maschinenbau. The $6300 \mathrm{kN}$ press is set to $50 \mathrm{kN}$ clamping force for CWR experiments. The roll gap is ensured by spacer discs with standardized heights, which act as a vertical end stop. In order to keep the effort and costs of this investigation low, an already existing CWR tool geometry is used, which is designed for the production of shafts with bearing seats.

As stated in Section 1.3, CWR can be performed at different temperatures, depending on work piece material and process design. For the following investigations, only one workpiece temperature was considered. The influence of the workpiece temperature on the forming behavior of

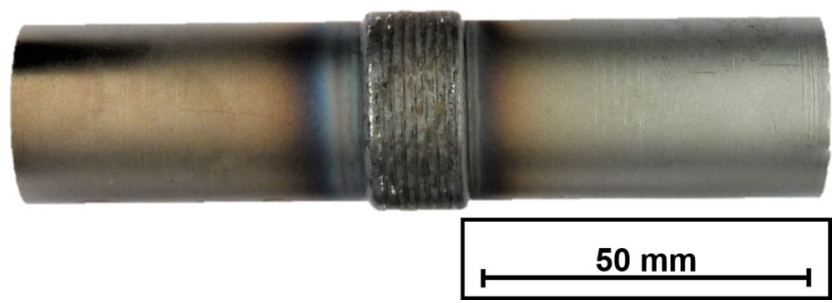

Fig. 5 C22.8 shaft with X2CrNiMo19-12 cladding applied by LHWC
Table 2 Welding parameters for LHWC

\begin{tabular}{lll}
\hline Parameter & Unit & LHWC \\
\hline Scanning speed & $\mathrm{mm} / \mathrm{min}$ & 1200 \\
Current & $\mathrm{A}$ & 70 \\
Wire feed rate & $\mathrm{m} / \mathrm{min}$ & 2.0 \\
Laser power & $\mathrm{kW}$ & 2.1 \\
Shielding gas flow (Argon) & $1 / \mathrm{min}$ & 6 \\
Wire diameter & $\mathrm{mm}$ & 1.0 \\
Stickout & $\mathrm{mm}$ & 6.5 \\
Seam-to-seam offset & $\mathrm{mm}$ & 1.6 \\
Laser beam source & - & LDM 3000-40 \\
Laser wavelength & $\mathrm{nm}$ & $1020-1060 \pm 15$ \\
\hline
\end{tabular}

hybrid shafts is currently being researched in other project areas. Heating of the parts before forming is done by either furnace or the IPH induction heating unit (manufactured by EMA-TEC GmbH). The advantage of the furnace compared to the induction unit is a more homogenous heating of the part. The induction heating unit creates slight gradients of temperature within the workpiece. Less scale on and less surface decarburization in the surface of the workpiece occurs due to the short heating time (60 s) used compared to the furnace (at least $40 \mathrm{~min}$ ). The use of a furnace would result in too little carbon remaining after the heating necessary for the CWR process. Especially in the surface of the bearing seat, which needs to be hardened, this would result in insufficient hardness for the intended use of the

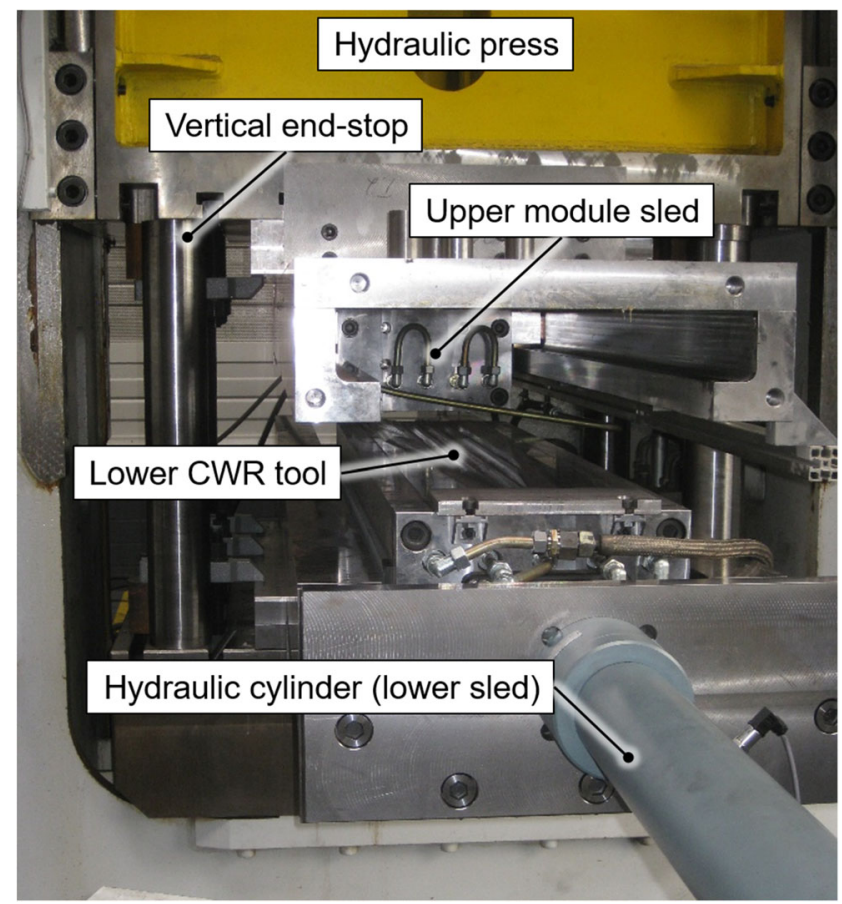

Fig. 6 Cross-wedge rolling test-stand at IPH 
part after rolling and milling. For this reason, the workpieces are heated by induction heating for these investigations. The workpieces are heated for $60 \mathrm{~s}$, inducing about $0.4 \mathrm{kWh}$ of energy into the workpiece, resulting in a peak temperature of $1300{ }^{\circ} \mathrm{C}$ before the $20 \mathrm{~s}$ manual transport into the CWR module. After transport, the workpiece remains at a temperature of about $1250{ }^{\circ} \mathrm{C}$. The tools are heated prior to forming operation to $150{ }^{\circ} \mathrm{C}$ using cartridge heaters. The bottom of each tool is insulated with a polymer plate made of AS600M to reduce temperature losses. The semifinished products are placed with their cladding aligned with the centers of the bearing seat forming wedges. A mechanical end stop ensures correct positioning within the tools. After manual positioning, the upper tool is lowered onto the vertical end stops with a force of $50 \mathrm{kN}$, resulting in a defined rolling gap of $28 \mathrm{~mm}$. As soon as the intended gap width is reached, the hydraulic cylinders of the die sleds are pressurized to start the rolling process, which lasts approx. $9 \mathrm{~s}$. The rolling process is continued until the end of the CWR tools is reached. After rolling, the workpieces are removed from the CWR module and placed on a steel frame structure to cool slowly in air at room temperature (approx. $20^{\circ} \mathrm{C}$ ) with free convection to avoid hardening and distortion.

\subsection{Turning and deep rolling}

After CWR the hybrid shafts are machined in the final step. Thereby, not only the target geometry of the component is set, but especially the final surface and subsurface properties of the component. In this context the influence of different machining processes (turning and deep rolling) on the surface and subsurface properties is investigated.

The machining experiments were carried out on a Gildemeister CTX420 linear lathe (manufactured by DMG Mori AG). Cylindrical hybrid shafts with a material transition in radial direction were turned as well as turned and then deep rolled (see Fig. 7). For the turning experiments coated indexable cemented carbide inserts DNMA 150612 WAK20 with a symmetric cuttingedge rounding of $\overline{\mathrm{S}}=30 \mu \mathrm{m}$ were used. In order to prevent an influence of cooling lubricant on the subsurface properties, the turning experiments were carried out without lubricant. The process parameters are shown in Table 3.

For the deep rolling experiments the indexable insert of the turning tool was replaced by a hydrostatic rolling tool HG6 with a ball diameter of $d_{b}=6.35 \mathrm{~mm}$. For statistical validation, the test series for the respective machining process were repeated five times. During the machining experiments, the process forces were measured with a 3-component dynamometer by Kistler Instrumente $\mathrm{GmbH}$.
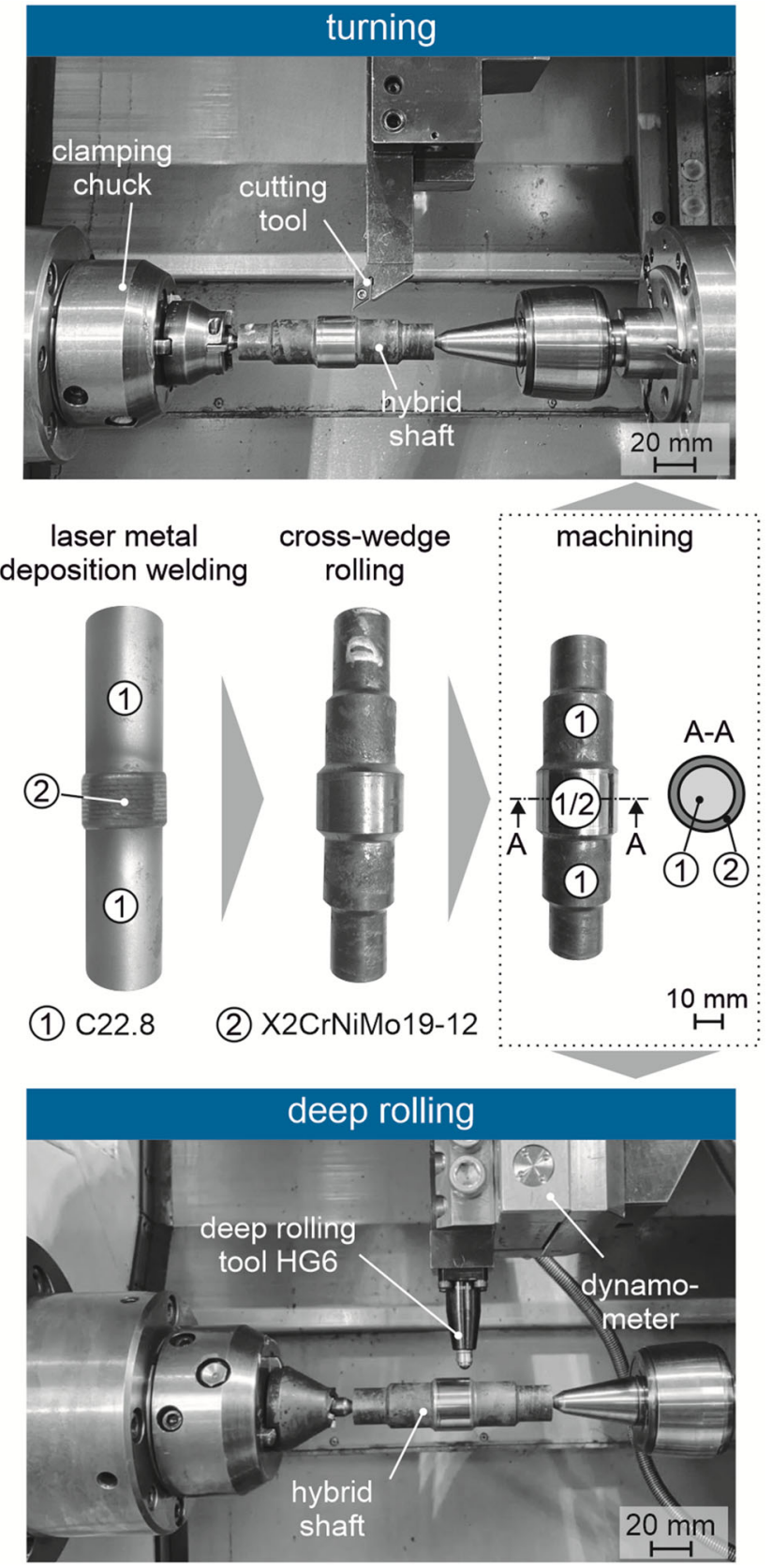

Fig. 7 Process chain and experimental setup on the CTX420 linear machine tool

Table 3 Experimental parameters of the machining processes

\begin{tabular}{llll}
\hline Parameter & Unit & Turning & Deep rolling \\
\hline Cutting speed $v_{c}$ & $\mathrm{~m} / \mathrm{min}$ & 120 & - \\
Feed $f$ & $\mathrm{~mm}$ & 0.1 & - \\
Depth of cut $a_{p}$ & $\mathrm{~mm}$ & 0.1 & - \\
Rolling speed $v_{r}$ & $\mathrm{~m} / \mathrm{min}$ & - & 120 \\
Overlap $u$ & $\%$ & - & 65 \\
Rolling pressure $p_{r}$ & $\mathrm{MPa}$ & - & 20 \\
\hline
\end{tabular}




\subsection{Residual stress measurements}

Due to different thermal expansion coefficients of the respective materials, delayed cooling of the subsurface and core, as well as local deformations, residual stresses were caused and changed after each process step. Residual stresses have a significant influence on the application behavior and consequently the lifetime of a component. Depending on the stress case, tensile residual stresses can promote crack initiation and propagation and thus lead to premature failure of the component. Compressive residual stresses can prevent crack initiation in a specimen subjected to cyclic stress and thus lead to an extended lifespan. For this reason, the analysis of the change in residual stress states within the process chain and the possibilities of their specific adjustment are essential. Residual stress measurements were carried out via X-ray diffraction, using the $\sin ^{2} \psi$-method described by Macherauch and Müller [37]. The measurements were carried out on an XRD 3003TT two circle X-ray diffractometer by Agfa NDT Pantak Seifert $\mathrm{GmbH} \& \mathrm{Co} . \mathrm{KG}$ with a $\mathrm{Cr}$ tube and a position sensitive detector. The point focus measuring spot was delimited with a $2 \mathrm{~mm}$ point collimator. The measurements were performed in $\omega$-mode. For the X-ray investigations $\mathrm{Cr} \mathrm{K} \alpha$ radiation was used. The measurement was performed on the iron lattice hkl 220. The $\sin ^{2} \psi$ method was applied with a variable Bragg angle between $125.0^{\circ}$ and $130.95^{\circ}$ with a step size of $0.05^{\circ}$ and measuring time per step of $144 \mathrm{~s}$ for $\gamma$-Fe. For $\alpha$-Fe a Bragg angle between $152.0^{\circ}$ and $159.975^{\circ}$ with a step size of $0.025^{\circ}$ and measuring time per step of $144 \mathrm{~s}$ was used. Nine tilt angles between $+45^{\circ}$ and $-45^{\circ}$ according to $\sin ^{2} \psi$ distribution were taken. The maximum information depth of the Xradiation was $\tau_{\max }=5.5 \mu \mathrm{m}$. For the determination of residual stress depth distributions, material was stepwise removed by electrolytic polishing. Electrolyte A2 $(60 \%$ perchloric acid) from Struers was used for material removal. The step size was $10 \mu \mathrm{m}$ until the residual stress minimum was reached and was then adjusted individually according to the specimen to be measured with regard to the step size. The step size was subsequently varied between $20 \mu \mathrm{m}$ and $100 \mu \mathrm{m}$. A number of 25 to 31 depth ablations were performed per specimen depending on the material transition. The evaluation of the measured data set was finally carried out with the RayfleX software by General Electric $\mathrm{GmbH}$.

\subsection{Surface roughness measurements}

After machining, the surface topography is measured using Confovis TOOLinspect by the company Confovis $\mathrm{GmbH}$. The Confovis microscope is based on the method of confocal measurement and focus variation. A measuring range of $5.6 \mathrm{~mm} \times 2.3 \mathrm{~mm}$ is selected for the evaluation of surface topography and roughness characteristics. The surface data are recorded with a $10 \times$ magnifying lens. The measured data sets are then processed with the Mountains Map 7.1 software from Digital Surf GmbH.

\subsection{Metallographic investigations, hardness and layer distribution measurements}

After each process step cross-sections are made to investigate cladding layer distribution, hardness and microstructure. Layer thickness and width are determined and evaluated with regard to their change in the process chain. Microhardness measurements for each process step are carried out at three different cross sections and three different positions. For a metallographic examination of the cladding material and the base material cross-sections are etched with V2A etchant, Aqua regia etchant and 2\% Nital etchant.

\section{Results and discussion}

\subsection{Cladding layer distribution}

The cladding had an initial height of $1.4 \mathrm{~mm}$ and a width of $14.4 \mathrm{~mm}$, resulting in a component diameter of $29.8 \mathrm{~mm}$ in the area of the later bearing seat. Due to the dilution with the base material, the maximum cladding thickness is $1.7 \mathrm{~mm}$.

The diameter of the bearing seat is reduced during CWR to a diameter of approximately $28 \mathrm{~mm}$. This leads to a thinner and wider distribution of the cladding. The cladding thickness is reduced to $1.5 \mathrm{~mm}$ while the width is increase to approximately $20 \mathrm{~mm}$. The layer distribution after crosswedge rolling is not symmetrical (see Fig. 8). The bearing seat is not completely covered with a cladding layer. This is due to an unfavourable positioning of the shaft when it is inserted into the CWR module. Turning further reduces the diameter in the area of the bearing seat. The diameter of the bearing seat is reduced to $27 \mathrm{~mm}$, which is the final dimension required for the bearing and the scale layer created during cross-wedge rolling is removed. The layer thickness decreases to around $0.85 \mathrm{~mm}$ and remains constant during the subsequent deep rolling process.

\subsection{Microstructure and hardness}

Due to deviations of the position of the shaft from the optimum starting position during insertion in the CWR module, the layer distribution is asymmetrical after this and all subsequent process steps. The bearing seat is not completely covered with a cladding layer.

However, the existing cladding layer in the bearing seat area is sufficient to perform all measurements regarding 
Fig. 8 Distribution of cladding layer after different process steps
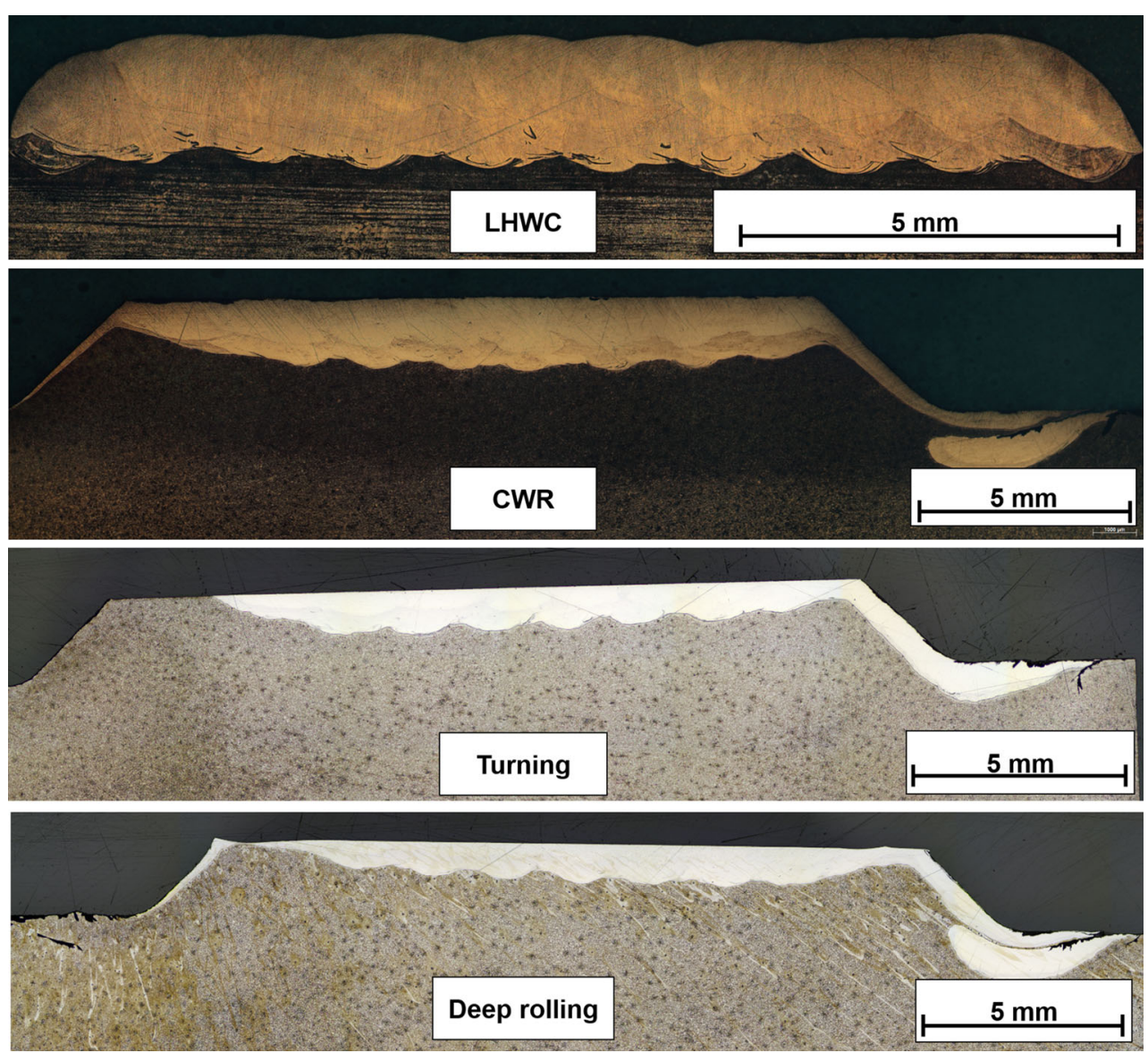

hardness, residual stress and surface roughness in a valid measuring area with the cladding present. The position of the microhardness measurements after the process steps are shown in Fig. 9. Each measurement consists of 45 measurement points with a distance of $0.1 \mathrm{~mm}$ between them.
The microhardness profile after laser hot-wire cladding is shown in Fig. 10. Hardness values of 200 HV0.1 in the cladding material and $150 \mathrm{HV} 0.1$ in the base material were achieved. The values correspond well to the expected values based on the tensile strength of the materials. A maximum hardness of 305 HV0.1 is found in in the transition area
Fig. 9 Position of

microhardness measurements after laser hot-wire cladding (a), planned (b) and actual (c) measurement positions after cross-wedge rolling, turning and deep rolling
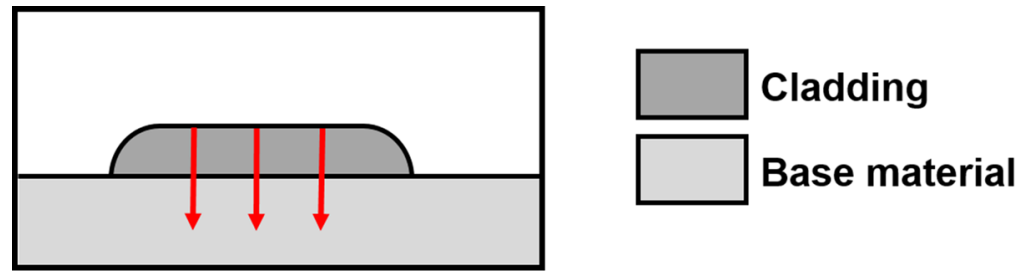

a)

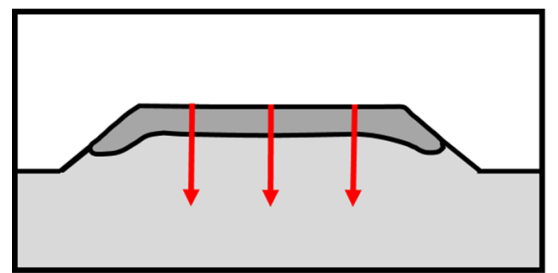

b)

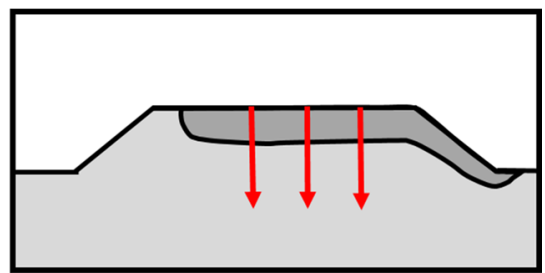

c) 


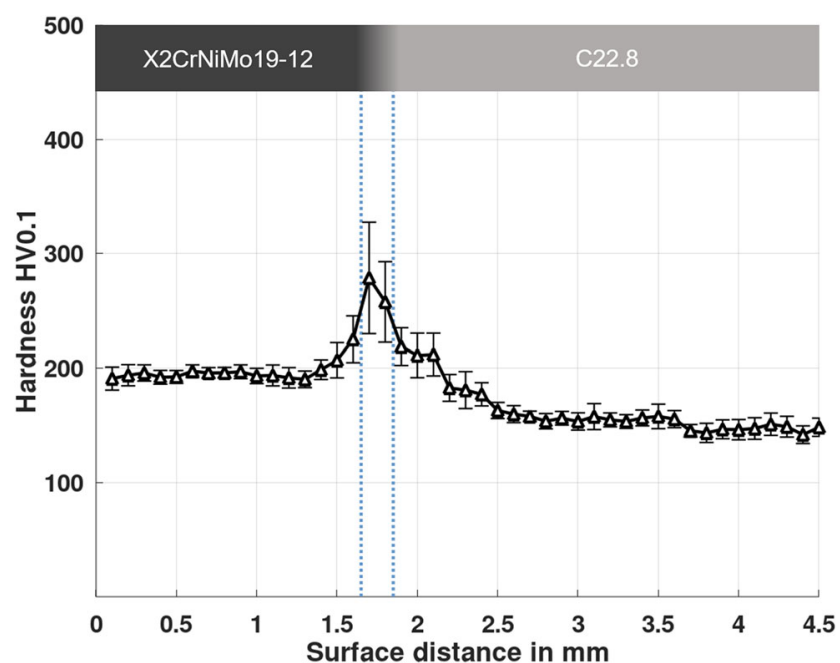

Fig. 10 Microhardness profile in a hybrid shaft after laser hot-wire cladding

from cladding to base material. An EDX analysis of the chemical composition is performed in the transition area. A linescan reveales that the chromium and nickel content in the transition area are lower than in the rest of the cladding. While a chromium content of 14 to $16 \%$ and a nickel content of $8-10 \%$ are found in the cladding, the chromium content is at 9.5 to $11.5 \%$ and the nickel content is at 6 to $8 \%$ in the transition area. Due to the lower content of the two beforementioned elements, a drop in hardness would be expected in the transition area. However, this is not consistent with the measured hardness values in this area. A XRD analysis for further microstructural investigations could not be successfully performed due to the small transition area. The cause of the hardness peak can therefore not be fully clarified.

The base material microstructure contains a combination of ferrite and perlite which is typical for a low carbon steel like C22.8. Due to the heat exposure during the welding process plates of Widmanstätten ferrite are observed in the heat-affected zone. (Fig. 11)

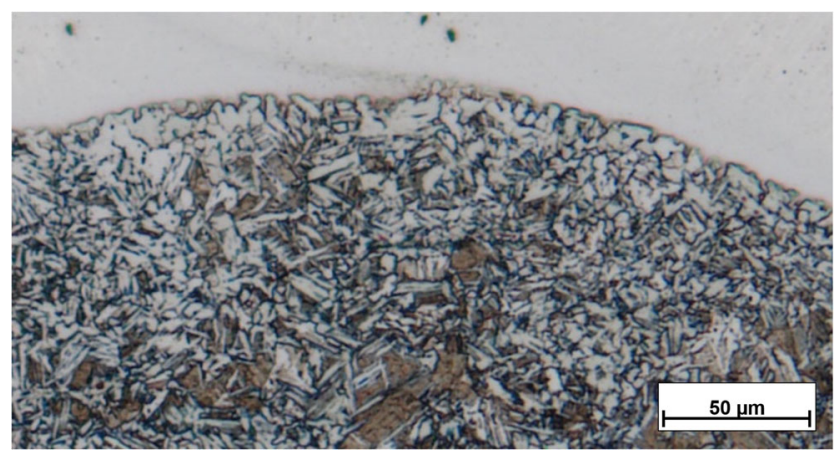

Fig. 11 Microstructural evolution in the base material of a hybrid shaft after deposition welding (etched with $2 \%$ Nital etchant)

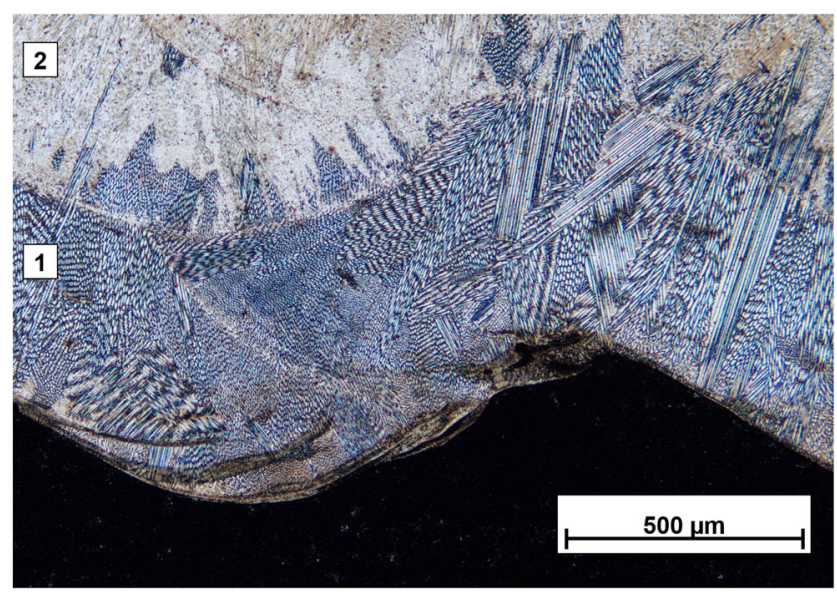

Fig. 12 Microstructural evolution in the cladding of a hybrid shaft after deposition welding (etched with V2A etchant)

The microstructure of the cladding material is shown in Fig. 12. The cladding material $\mathrm{X} 2 \mathrm{CrNiMo19-12}$ is located in the brighter area in the upper part of the figure. It is solidified in a austenitic microstructure. During welding of the second cladding layer (Fig. 12 - marked with number 2) the first layer (marked with number 1) is heat treated which leads to the formation of needle-like grains.

After CWR the microstructure in the base material is homogeneous without Widmannstätten ferrite (see Fig. 13). The needle-like grains in the first cladding layer are turned into a homogeneous austenitic microstructure (see Fig. 14). The transformation of the welding microstructure in a classic forming microstructure after hot forming has been shown in previous work [1].

The microhardness profile after CWR is shown in Fig. 15. Hardness values of 150-170 HV0.1 are found in the base material while hardness values between $200 \mathrm{HVO} 0.1$ and $250 \mathrm{HVO} 0.1$ are found in the cladding material.

After turning, an increase in the hardness values of the cladding material between $240 \mathrm{HV} 0.1$ and $270 \mathrm{HV} 0.1$ can be noticed. The highest hardness value of $300 \mathrm{HV} 0.1$

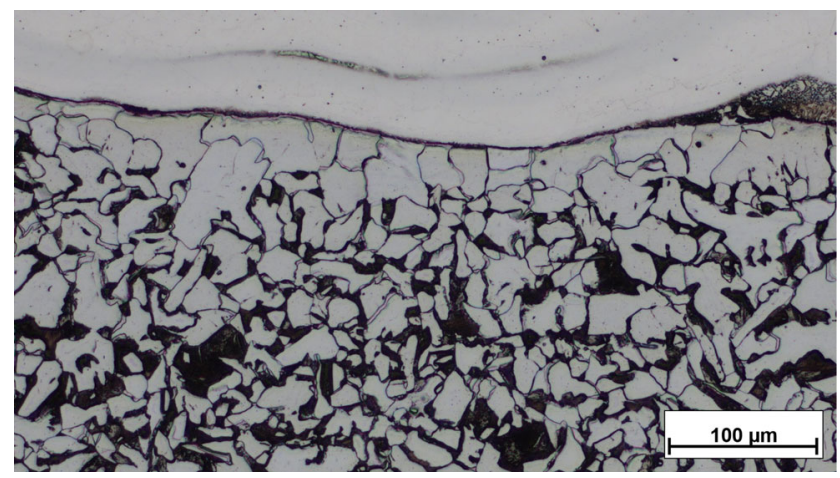

Fig. 13 Microstructural evolution in the base material of a hybrid shaft after cross-wedge rolling (etched with $2 \%$ Nital etchant) 


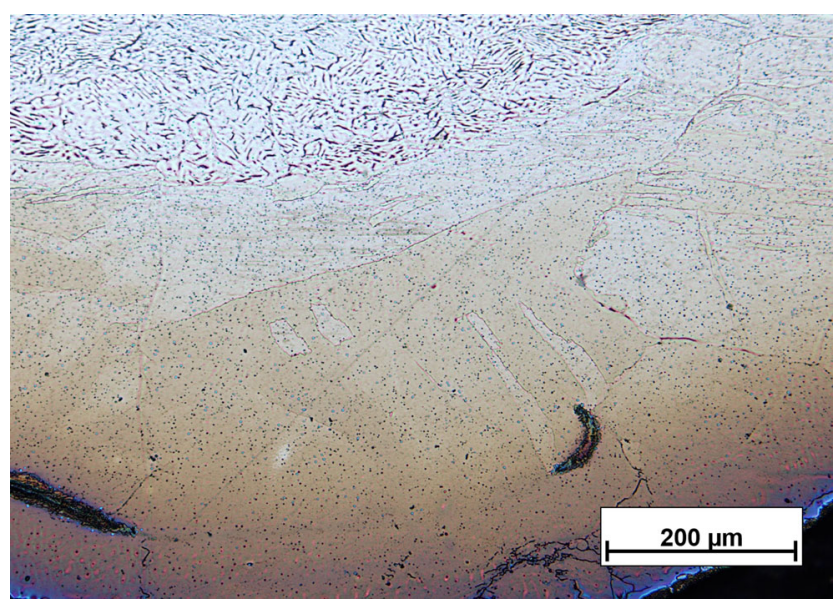

Fig. 14 Microstructural evolution in the cladding of a hybrid shaft after cross-wedge rolling (etched with V2A etchant)

is found in the transition zone from cladding to base material. The reason for the increased hardness compared to LHWC and CWR is that during turning the surface and subsurface is subjected to thermal as well as mechanical stress. The mechanical stress leads to a compression and enhancement of the dislocation density of the material and consequently to an increase in the hardness values. With further penetration depth the hardness values drop rapidly and remain constant at a value of 160 HV0.1 in the base material. The microhardness profile after turning is shown in Fig. 16.

The microhardness profile after deep rolling is shown in Fig. 17. A maximum hardness of 370 HV0.1 is found near the surface of the shaft. The hardness in the cladding layer decreases steadily with increasing depth to a value of $155 \mathrm{HV} 0.1$, which is equivalent to the hardness of the base material. In deep rolling, the material is only

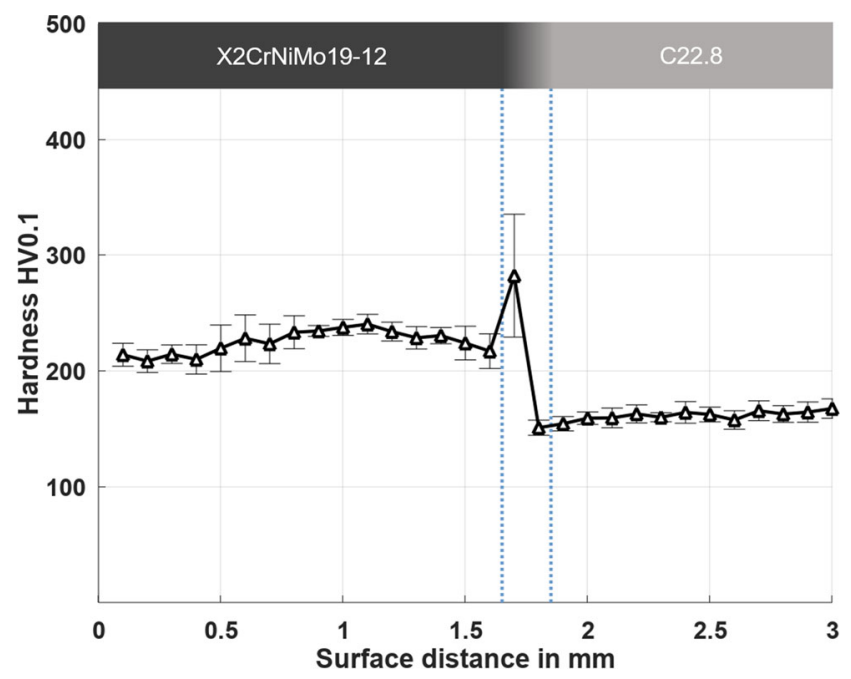

Fig. 15 Microhardness profile in a hybrid shaft after cross-wedge rolling

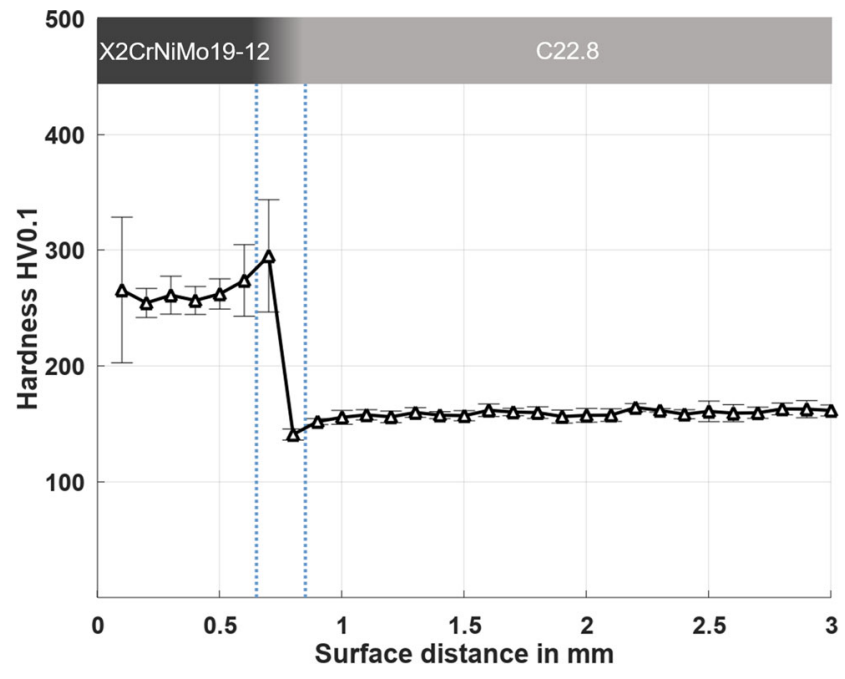

Fig. 16 Microhardness profile in a hybrid shaft after turning

subjected to mechanical stress. Here, the Hertzian pressure has an effect on the harder cladding material. Hertzian pressure leads to significant work hardening of the surface and subsurface. Consequently, the highest hardness values within the process chain are observed after deep rolling. The cladding thickness varies due to batch differences. The fact that the transition area is at a greater depth after deep rolling than after turning is due to these batch differences and is not caused by a physical effect during deep rolling.

The microstructure in the cladding after turning and after deep rolling is shown in Fig. 18. An austenitic microstructure with chrome precipitations is present. A comparison of the microstructure after these two process steps shows that an anisotropy in axial direction can be observed in the microstructure after deep rolling.

While the hardness of the base material remains constant at 150-170 HV0.1 the hardness of the cladding layer

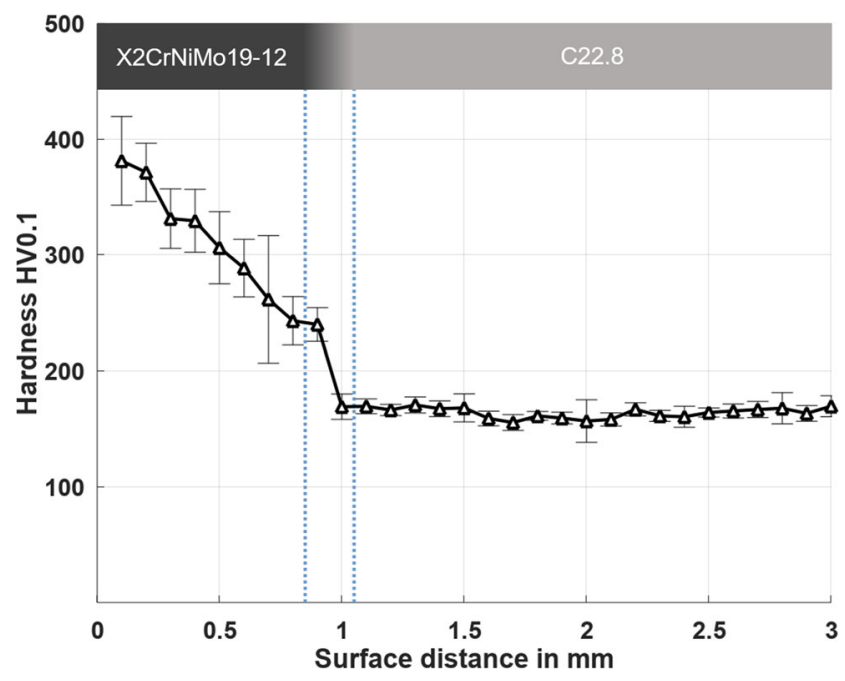

Fig. 17 Microhardness profile in a hybrid shaft after deep rolling 

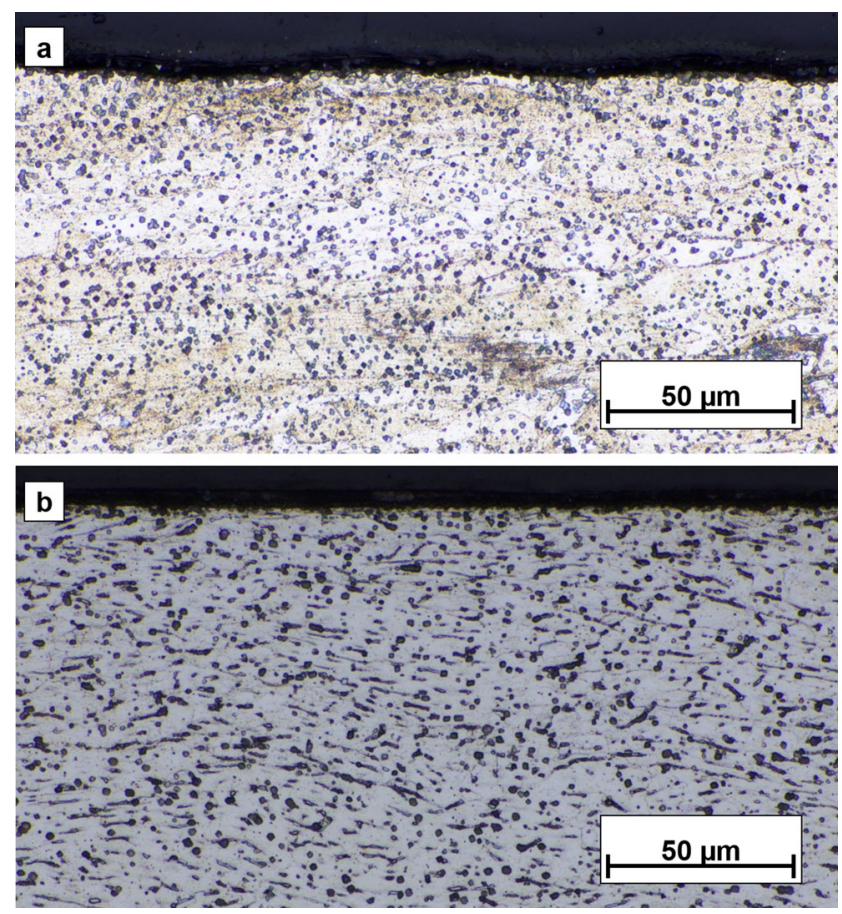

Fig. 18 Microstructural evolution in the cladding material of a hybrid shaft after turning (a) and deep rolling (b) (etched with Aqua regia etchant)

is subject to change in the different process steps. The hardness values of the base material are comparable to the hardness values obtained in previous investigations of Tailored Forming process chains with the same base material $[3,4]$.

\subsection{Process forces and residual stress state}

Process forces are a function of the mechanical stress that a component is subjected to during machining. In particular, passive forces act in the process like a Hertzian pressure and are therefore directly related to the resulting residual stresses [38]. Compared to the residual stresses, however, process forces can be determined relatively easily in the process. The dispersion of the process forces in the machining process can therefore be used to determine the dispersion of the residual stresses in the component. For this reason, process forces are monitored during machining to determine the extent of the residual stress measurements required. Figure 19 shows the respective force profiles. The experimental series were repeated five times for statistical validation. The force profiles show that the deviation is almost neglectable.

While turning, the passive force $F_{p}$ of approx. $200 \mathrm{~N}$ is the maximum force component. At approx. $100 \mathrm{~N}$, the cutting force $F_{c}$ is only half as high as the passive force and the feed force $F_{f}$ is insignificantly small compared to
Table 4 Nomenclature

\begin{tabular}{ll}
\hline$a_{p}$ & Depth of cut \\
$b$ & Diameter of contact ellipse in feed direction \\
$d_{b}$ & Ball diameter \\
$v_{c}$ & Cutting speed \\
$v_{r}$ & Rolling speed \\
$E$ & Young's modulus \\
$f$ & Feed \\
$F_{c}$ & Feed force \\
$F_{p}$ & Passive force \\
$F_{p N}$ & Normal rolling force \\
$k$ & Curvature \\
$v$ & Poisson's ratio \\
$\Theta$ & Bragg angle \\
$\sigma_{\perp}$ & Resiudal stress transvers to machining direction \\
$\sigma_{\|}$ & Residual stress parallel to machining direction \\
$\sigma_{r}$ & Stress radial to the ball \\
$\sigma_{z}$ & Load stress in z-direction \\
$\bar{S}$ & Cutting edge rounding $S_{\alpha} / S_{\gamma}$ \\
$\tau_{\text {max }}$ & Maximum shear stress \\
$\eta$ & 1. Coefficient at the contact of differently curved bodies \\
$p_{\text {max }}$ & Hertzian pressure \\
$p_{r}$ & Rolling pressure \\
$u$ & Overlap \\
$\xi$ & 2. Coefficient at the contact of differently curved bodies \\
$z$ & Distance from surface \\
\hline & \\
\hline &
\end{tabular}

the previously mentioned forces. In deep rolling, only the rolling force $F_{p}$ is dominant. The feed force $F_{f}$ and normal rolling force $F_{p N}$ (force perpendicular to the rolling force) are negligibly small and are not shown for the purpose of overview. The rolling force $F_{p}$ of approx. $900 \mathrm{~N}$ is clearly distinguishable from the turning force profiles. The large mechanical stress on the deep rolled specimen indicates high compressive residual stresses in its subsurface.

In the state of the art the deep rolling process is often described by an idealised Hertzian contact, taking into account the simplifications listed below. It is assumed that a stationary rolling ball is pressed onto a cylinder; rolling of the ball is not taken into account. The material behaviour is assumed to be isotropic and homogeneous. Furthermore, an ideal elastic behaviour is assumed. When a ball comes into contact with a cylinder, a contact ellipse is created with the maximum Hertzian pressure $p_{\max }$ in the center. The calculation of the maximum Hertzian pressure $p_{\max }$ is carried out according to [39] with

$p_{\text {max }}=\frac{1}{\xi \eta} \sqrt[3]{\frac{3 F_{p} E^{2}\left(\sum k\right)^{2}}{8 \pi^{2}\left(1-v^{2}\right)^{2}}}$ 
Fig. 19 Process forces during turning and deep rolling of the hybrid shaft
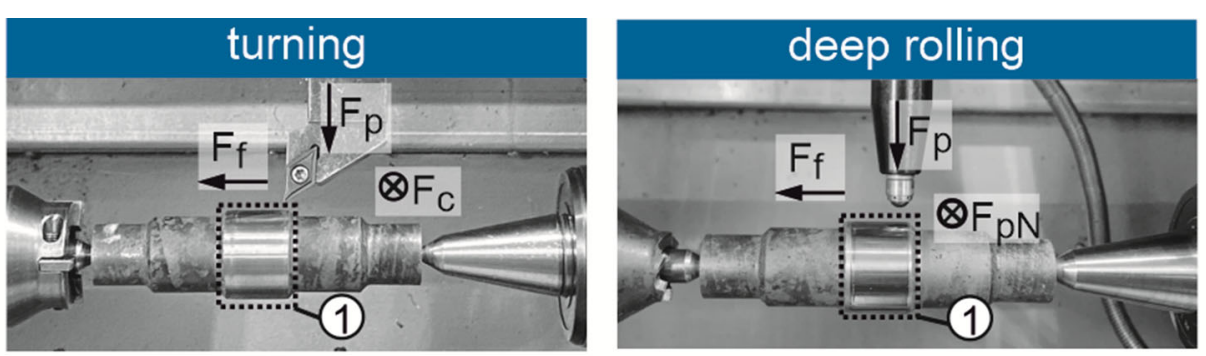

(1) machined area X2CrNiMo19-12

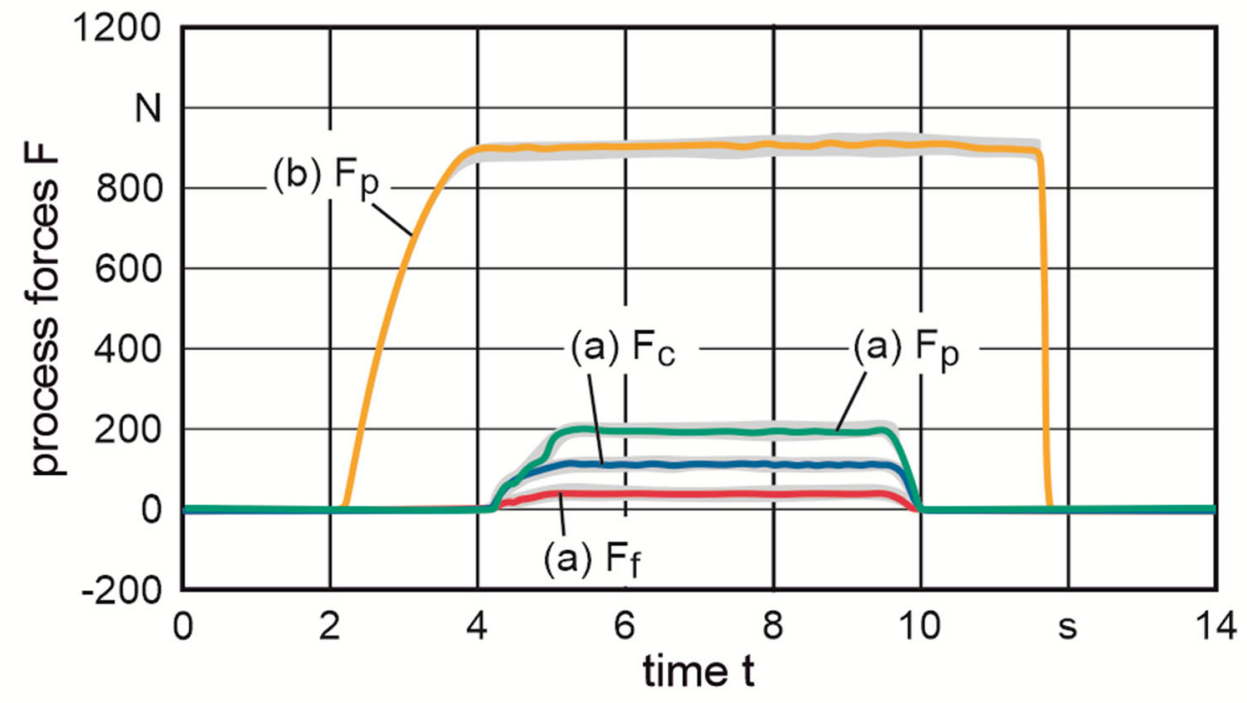

machining process

(a) turning

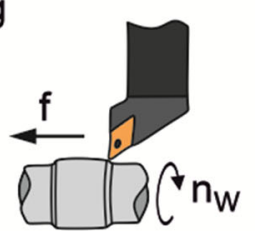

(b) deep rolling

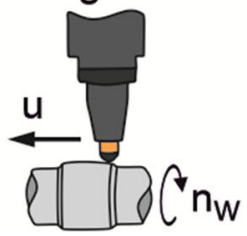

\section{experimental parameters}

(a)

$\begin{array}{lll}\text { cutting speed } v_{c} & =120 \mathrm{~m} / \mathrm{min} \\ \text { depth of cut } a_{p} & =0.1 \mathrm{~mm} \\ \text { feed } \mathrm{f} & =0.1 \mathrm{~mm} \\ \text { cutting edge rounding } \bar{S} & =30 \mu \mathrm{m}\end{array}$

(b)

$\begin{array}{ll}\text { deep rolling velocity } \mathrm{v}_{\mathrm{r}} & =120 \mathrm{~m} / \mathrm{min} \\ \text { ball diameter } \mathrm{d}_{\mathrm{b}} & =6.35 \mathrm{~mm} \\ \text { rolling pressure } \mathrm{pr}_{\mathrm{r}} & =20 \mathrm{MPa} \\ \text { overlap } \mathrm{u} & =65 \%\end{array}$

$\xi$ and $\eta$ are the contact coefficients of differently curved surfaces and $\sum \mathrm{k}$ is the sum of the individual curvatures of the ball and the cylinder (Table 4). For the investigated parameter combination, the maximum Hertzian pressure is $p_{\max }=8.7 \mathrm{GPa}$. According to the following equations 24 of [39] the stress distributions for the used deep rolling process can be calculated.

Stress in z-direction $\sigma_{z}$

$\sigma_{z}=-p_{\max }\left(\left(\frac{z}{b}\right)+1\right)^{-1}$
Stress radial to the ball $\sigma_{r}$

$\sigma_{r}=-p_{\max }\left[(1+v) \cdot\left(1-\frac{z}{b} \cdot \arctan \left(\frac{z}{b}\right)\right)-\frac{1}{2\left(\frac{z}{b}\right)^{2}+1}\right]$

Maximum shear stress $\tau_{\max }$

$\tau_{\max }=-p_{\max }\left[\frac{1+v}{2} \cdot\left(1-\frac{z}{b} \cdot \arctan \left(\frac{z}{b}\right)\right)-\frac{3}{4\left(\frac{z}{b}\right)^{2}+1}\right]$ 
with Poisson's ratio $v$ and diameter of the contact ellipse in feed direction $b$.

Figure 20 shows the stress distributions for the stresses in the direction of the component core $\sigma_{z}$, radially to the contact surface $\sigma_{r}$ and the maximum occurring shear stresses $\tau_{\max }$ for the used ball diameter of $6.35 \mathrm{~mm}$ and the rolling pressure of $20 \mathrm{MPa}$. For this study, the simplifications mentioned above are assumed and the deep rolling process is considered as a momentary snapshot. The comparison of the depth effect of the deep rolling process is only valid for step 4 in Fig. 21.

During deep rolling, an elastoplastic deformation of the material takes place. Elastic deformations are based on reversible distortions of crystal lattices. Plastic deformations are irreversible and occur when stresses generated in the material exceed the yield stress of the material. Considering the stress distribution in the contact zone between tool and

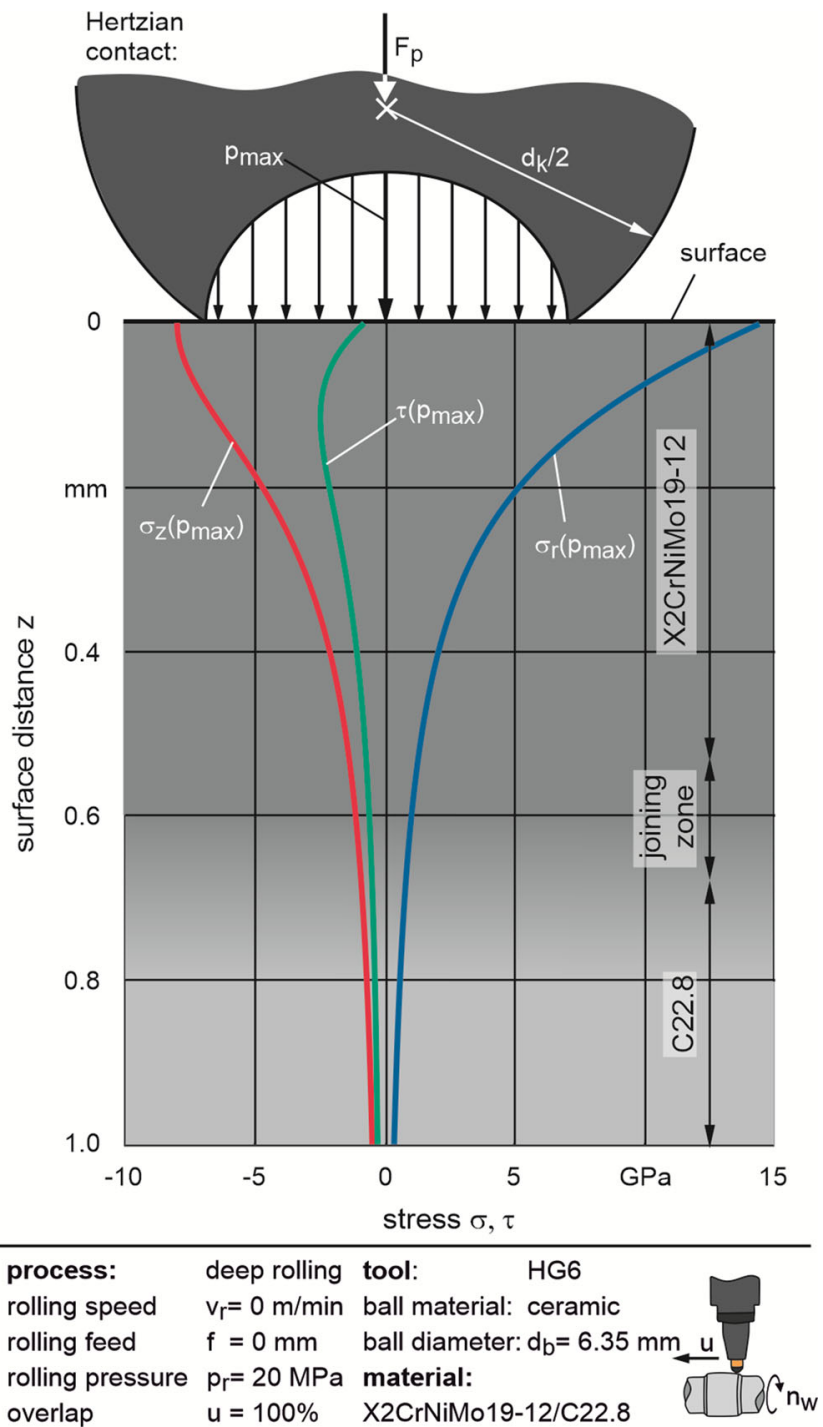

Fig. 20 Stress distribution in the Hertzian contact for deep rolling
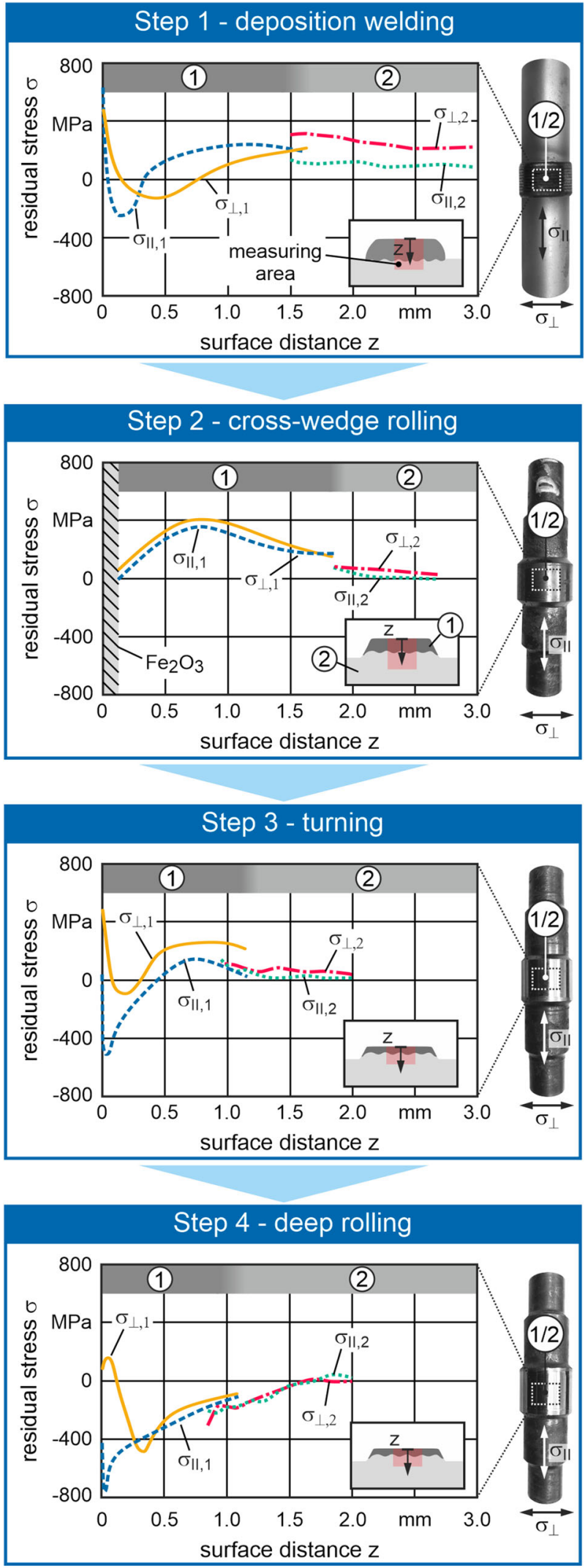

(1) $\mathrm{X} 2 \mathrm{CrNiM} 19-12 \quad$ (2) $\mathrm{C} 22.8$

Fig. 21 Residual stress depth profiles after each process step within the process chain 
workpiece, it becomes clear that the stresses extend into the depth. At a depth of 0.6 to $0.8 \mathrm{~mm}$, where the material transition area is located, stresses of $1-1.5 \mathrm{GPa}$ are still existing, which could lead to a limited influence of the residual stress state of the base material. In order to verify whether plastic deformation is actually taking place in this region, the von Mises shape deformation energy hypothesis can be used with the calculation of the equivalent stress $\sigma_{v}$ as an indicator for plastic deformation. In the depth range mentioned before, where the material transition takes place, the von Mises equivalent stress is approx. $450 \mathrm{MPa}$. The slight exceeding of the yield point of the base material of $410 \mathrm{MPa}$ results in plastic deformation, which would explain the change in residual stresses in this transition area, which is reflected in the results of the residual stress measurements.

During turning, there is also thermal load in addition to the mechanical load. Consequently, the resulting residual stress state is a superposition of the two types of loads. The results of the residual stress measurements within the process chain are displayed in Fig. 21. Due to the negligible variation of the process forces, the residual stress measurements were only carried out on one sample at a time, representative of all the samples investigated. By this $\sigma_{\|}$represents the residual stresses in the axial direction and $\sigma_{\perp}$ the residual stresses in the circumferential direction of the component. With the help of an X-ray phase analysis, it could be determined that the retained austenite content in $\mathrm{X} 2 \mathrm{CrNiMo19-12}$ is significantly higher than in C22.8. Therefore, the residual stresses in X2CrNiMo19-12 were measured at the gamma iron peak and the residual stresses in $\mathrm{C} 22.8$ at the alpha iron peak. In the joining zone, elements of both materials are present. Therefore measured residual stress values were recorded for both gamma iron (X2CrNiMo19-12) and alpha iron (C22.8). The residual stress depth profiles show the actual changes in residual stress after each process step. Regardless of the manufacturing or machining process, the compressive residual stresses are always higher in the axial direction than in the circumferential direction of the shaft. This means that the plastic deformations are higher in the axial direction. After laser hot-wire cladding, very high tensile residual stresses are observed in the surface because of high temperature impact. With increasing penetration depth, compressive residual stresses are formed. A compressive residual stress maximum of $-250 \mathrm{MPa}$ is found at a surface distance of approx. $140 \mu \mathrm{m}$ in the cladding material $\mathrm{X} 2 \mathrm{CrNiMo19-12}$. With further increase of the penetration depth, the residual stresses are shifted towards tension. At a surface distance of $1.5 \mathrm{~mm}$, the material transition zone from the cladding material to the base material is reached. It is noticeable that the residual stresses in the transition zone are at a similar level and transfer almost continuously into the base material. In the base material, however, only tensile residual stresses are observed up to the investigated depth. This does not change in the further course of the process chain. The reason for tensile stresses in the cladding after deposition welding is that in these processes the shafts are subject to very high thermal stresses.

If a comparison is now made between the residual stress depth profiles after cross-wedge rolling (step 2) and deposition welding (step 1), it is noticeable that the sample investigated only has tensile residual stresses in the investigated subsurface. The amount of tensile residual stress increases from the surface to a depth of $0.7 \mathrm{~mm}$ and then decreases with a further advance. In the material transition zone, a residual stress gradient is visible, whereby the base material is almost stress free or affected by low tensile residual stresses. Due to the compressive deformation in radial direction during CWR compressive residual stresses are induced in the hybrid part. This causes the before mentioned shift of the residual stress in the base material. In the cladding, this effect is superimposed by two other effects. The higher coefficient of thermal expansion of the cladding material leads to the formation of tensile residual stresses in the cladding during cooling after crosswedge rolling. The thermal shrinkage of the cladding is restricted by the base material, which only shrinks to a lesser extent during cooling. Furthermore, the inhomogeneous temperature profile in the component during cooling in air can enhance this effect.

The material transition zone after turning and deep rolling already starts at approx. $0.9 \mathrm{~mm}$. The reason for this is a material separation during the turning process in order to set the diameter to size. Consequently, the distance of the joining zone from the surface of the shaft is reduced. In the case of deep rolling, material separation no longer takes place; instead, massive elastoplastic micro forming of the surface and subsurface happens. Therefore, the distance from surface to the joining zone corresponds to that after turning.

Machining (turning and deep rolling) leads to a shift of the residual stresses in the direction of compression. The bow-shaped course of the residual stress depth profiles are characteristic for the machining process of hardened material. This means that for turning tensile residual stresses are measured on the component surface, which change into compressive residual stresses with increasing penetration depth until a maximum value of compressive residual stresses is reached. After reaching the maximum, the residual stresses are transferred back into the tensile range until they reach the stress-free state. The reason for this is the superposition of thermal and mechanical load during turning, which leads to tensile residual stresses in the surface and compressive residual stresses below the surface. In the case of deep rolling, this is due to forming 
processes such as expansion and compression processes, which already lead to compressive residual stresses in the surface, which increase with increasing surface distance and then run out in the direction of tensile residual stresses. As already known from the state of the art, higher compressive residual stresses can be determined below the surface after deep rolling than after turning. The reason for this is higher plastic deformation and thus higher mechanical stress on the material during deep rolling. However, the results of the residual stress investigations show that the residual stress profiles change significantly in the subsurface within the process chain. Here, not only the cladding material but also the residual stresses in the base material are changed within the process chain. A possible material correlation with changes of residual stress state after each process step
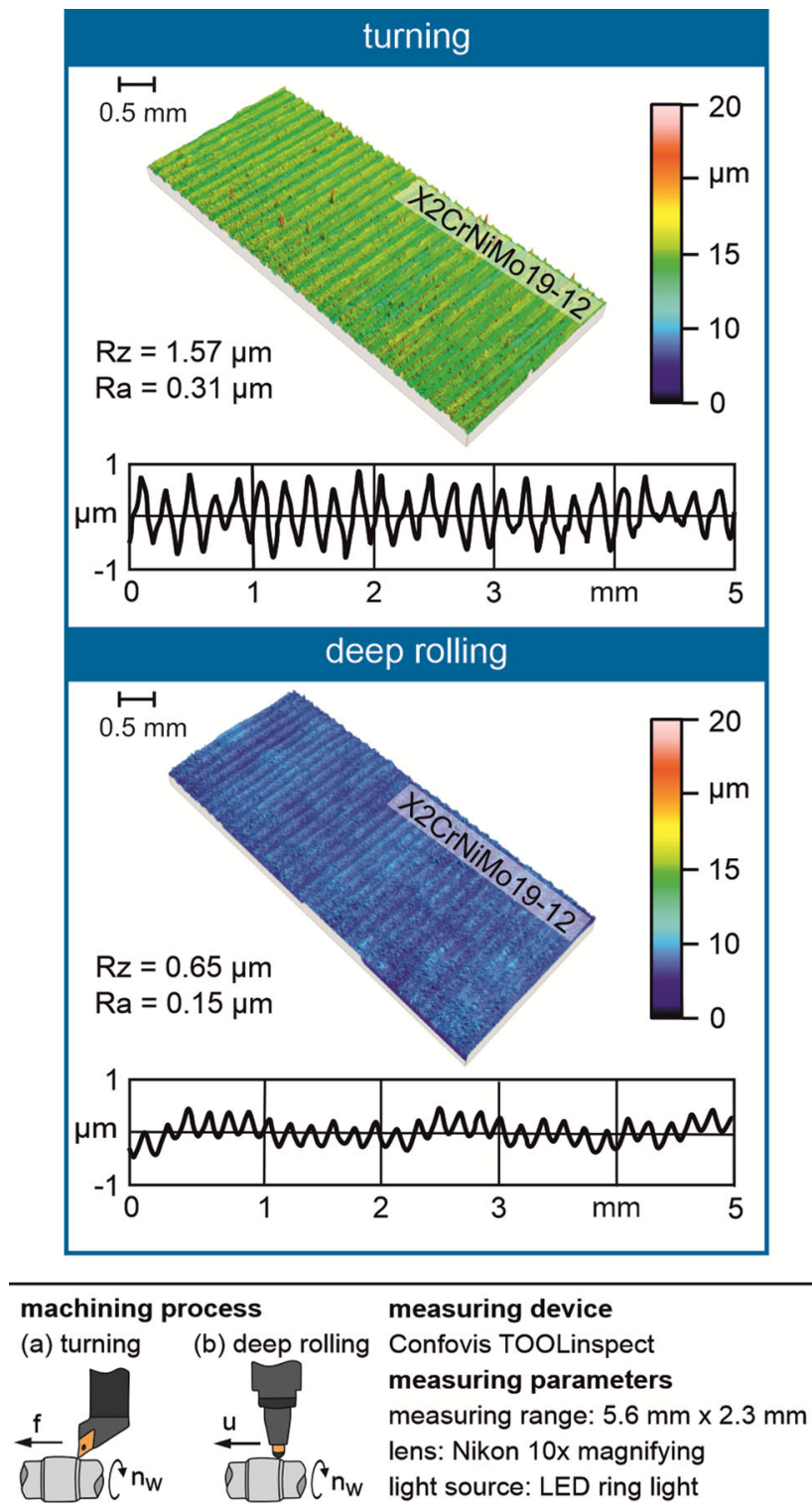

Fig. 22 Surface topography and roughness after turning and deep rolling or possibilities of influencing the final residual stress state through a modified initial residual stress state are to be investigated in future studies.

\subsection{Surface roughness measurements}

Surface topography and roughness after machining are displayed in Fig. 22. It is obvious that surface roughness decreases significantly after the machining process.

Differences between the individual machining processes turning and deep rolling are also clearly evident. While the roughness values after turning are in the range of $R_{z}=1.6 \mu \mathrm{m}$, the roughness value is reduced by $60 \%$ after deep rolling. This can also be seen in the roughness profiles in Fig. 22. The reason for this is the fact that the peaks of roughness caused by the previous turning process are lowered by the deep rolling process. During deep rolling, however, there is no material removal but a severe deformation. Consequently, the material that is deformed at the roughness peaks must flow into the roughness valley. This leads to an increase in the roughness depth and simultaneous reduction in the roughness peak. Therefore, a levelling of the surface topography takes place which was generated by the previously performed turning process. However, a complete elimination or smoothening of the turned surface is not the case.

\section{Conclusion}

In this study, it is shown that the application of the Tailored Forming process chain, consisting of the processes laser hot-wire cladding, cross-wedge rolling, turning and deep rolling, can be used to produce hybrid shafts of the material combination $\mathrm{C} 22.8$ and $\mathrm{X} 2 \mathrm{CrNiMo19-12}$. The hybrid shafts were successfully formed without layer separation. However, when cross sections were produced, it became apparent that the starting position had not been optimally selected for CWR. The cladding was not distributed symmetrically to the bearing seat as desired. However, the existing cladding layer in the bearing seat area was sufficient to perform the evaluation of the surface and subsurface properties of the cladding in a valid measuring area with the cladding present.

The advantage of the Tailored Forming process chain lies in the transformation of the welding microstructure into a forming microstructure and the associated improvement regarding the mechanical properties. It has been demonstrated that such an effect can be achieved on the material combination with an austenitic stainless steel as cladding material.

Due to the larger thermal expansion coefficient in the cladding material compared to the base material, the 
formation of tensile residual stresses in the cladding during cooling after CWR was expected. This could be verified in the course of the experiments.

Turning induces tensile residual stresses near the surface in radial direction which leads to a bow-shaped course of the residual stresses. In axial direction compressive residual stresses are induced to a depth of $0.5 \mathrm{~mm}$. The hardness of the cladding layer is increased by the turning process due to the thermal and mechanical stress.

As expected, surface roughness is reduced by a deep rolling process compared to the turned surface. Work hardening due to deep rolling leads to highest hardness values in the surface and subsurface within the process chain and to a shift of the stress state both in radial and axial direction from tensile to compressive residual stresses. Hardness in the near-surface area is significantly increased.

In this study, the process parameters were not varied within the individual process steps. Further investigations should therefore consider the influence of the parameters on the appropriate process steps as well as the resulting subsurface properties. Especially the influence of the initial subsurface state on the resulting subsurface properties after the respective process step must be investigated. The investigations should be extended to other material combinations in order to study the influence of the material properties on the surface and subsurface properties. These findings can be used for the specific adjustment of desired surface and subsurface properties of hybrid components. Furthermore, an investigation of the quality of the cladding in terms of corrosion resistance should be conducted. An investigation of the use of the austenitic cladding material with a high-strength material as part of a hybrid multimaterial cladding system should be carried out as well. The tensile residual stress state obtained after hot forming by cross-wedge rolling suggests that compressive residual stresses can be achieved in the outer cladding in these multimaterial cladding systems.

Author contribution Conceptualization, L.B., J.K., V.P.; investigation L.B., J.K., V.P., M.Y.F; supervision M.S., L.O., B.D., B.B., B.-A.B., T.H.; visualization L.B., J.K., V.P.; writing-original draft L.B., J.K., V.P., M.Y.F; writing—review and editing M.L., J.H., M.S., T.H., B.B., B.-A.B., B.D., L.O..

Funding Open Access funding enabled and organized by Projekt DEAL. This research was funded by the Deutsche Forschungsgemeinschaft (DFG, German Research Foundation)-CRC 1153, subproject A4, B1, B4 - 252662854

Availability of data and materials Data available on request from the authors.

\section{Declarations}

Conflict of interest The authors declare no competing interests.
Open Access This article is licensed under a Creative Commons Attribution 4.0 International License, which permits use, sharing, adaptation, distribution and reproduction in any medium or format, as long as you give appropriate credit to the original author(s) and the source, provide a link to the Creative Commons licence, and indicate if changes were made. The images or other third party material in this article are included in the article's Creative Commons licence, unless indicated otherwise in a credit line to the material. If material is not included in the article's Creative Commons licence and your intended use is not permitted by statutory regulation or exceeds the permitted use, you will need to obtain permission directly from the copyright holder. To view a copy of this licence, visit http://creativecommons. org/licenses/by/4.0/.

\section{References}

1. Blohm T, Nothdurft S, Mildebrath M, Ohrdes H, Richter J, Stonis M, Langner J, Springer A, Kaierle S, Hassel T, Wallaschek J, Overmeyer L, Behrens B-A (2018) Investigation of the joining zone of laser welded and cross wedge rolled hybrid parts. Int J Mater Form 11:829-837. https://doi.org/10.1007/s12289-017-1393-0

2. Jawahir IS, Brinksmeier E, M'Saoubi R, Aspinwall DK, Outeiro JC, Meyer D, Umbrello D, Jayal AD (2011) Surface integrity in material removal processes: recent advances. CIRP Annals 60(2):603-626. https://doi.org/10.1016/j.cirp.2011.05.002

3. Behrens B-A, Diefenbach J, Chugreeva A, Kahre C, Herbst S, Nürnberger F (2020) Tailored forming of hybrid bevel gears with integrated heat treatment. Procedia Manuf 47:301-308. https://doi.org/10.1016/j.promfg.2020.04.234

4. Chugreeva A, Mildebrath M, Diefenbach J, Barroi A, Lammers M, Hermsdorf J, Hassel T, Overmeyer L, Behrens B-A (2018) Manufacturing of high-performance bi-metal bevel gears by combined deposition welding and forging. Metals 8(11):898. https://doi.org/10.3390/met8110898

5. Coors T, Mildebrath M, Büdenbender C, Saure F, Faqiri MY, Kahra C, Prasanthan V, Chugreeva A, Matthias T, Budde L, Pape F, Nürnberger F, Hassel T, Hermsdorf J, Overmeyer L, Breidenstein B, Denkena B, Behrens B-A, Maier HJ, Poll G (2020) Investigations on tailored forming of AISI 52100 as rolling bearing raceway. Metals 10(10):1363. https://doi.org/10.3390/met10101363

6. Pape F, Coors T, Barroi A, Hermsdorf J, Mildebrath M, Hassel T, Kaierle S, Matthias T, Chugreev A, Behrens B-A, Overmeyer L, Poll G (2018) Tribological study on tailoredformed axial bearing washers. Tribol Online 13(6):320-326. https://doi.org/10.2474/trol.13.320

7. Behrens B-A, Chugreev A, Matthias T, Poll G, Pape F, Coors T, Hassel T, Maier HJ, Mildebrath M (2019) Manufacturing and evaluation of multi-material axial-bearing washers by tailored forming. Metals 9(2):232. https://doi.org/10.3390/met9020232

8. Saha MK, Das S (2016) A review on different cladding techniques employed to resist corrosion. JAEI 86(1-2):51-63. https://doi.org/10.22485/jaei/2016/v86/i1-2/119847

9. Khara B, Mandal ND, Sarkar A, Sarkar M, Chakrabarti B, Das S (2016) Weld cladding with austenitic stainless steel for imparting corrosion resistance. Indian Weld J 49(1):74-81. https://doi.org/10.22486/iwj/2016/v49/i1/125902

10. Barroi A, Zimmermann F, Hermsdorf J, Kaierle S, Wesling V, Overmeyer L (2016) Evaluation of the laser assisted double wire with nontransferred arc surfacing process for cladding. J Laser Appl 28(2):022306. https://doi.org/10.2351/1.4944001

11. Barroi A, Hermsdorf J, Prank U, Kaierle S (2013) A novel approach for high deposition rate cladding with minimal dilution 
with an arc - laser process combination. Phys. Procedia 41:249_ 254. https://doi.org/10.1016/j.phpro.2013.03.076

12. Ding D, Pan Z, Cuiuri D, Li H (2015) Wire-feed additive manufacturing of metal components: technologies, developments and future interests. Int $\mathrm{J}$ Adv Manuf Technol 81:465-481. https://doi.org/10.1007/s00170-015-7077-3

13. Tyralla D, Seefeld T (2019) Higher deposition rates in laser hot wire cladding (LHWC) by beam oscillation and thermal control. In: Wulfsberg JP, Hintze W, Behrens BA (eds) Production at the leading edge of technology. Springer Vieweg. Berlin, Heidelberg. https://doi.org/10.1007/978-3-662-60417-5_40

14. Barroi A, Albertazzi Gonçalves D, Hermsdorf J, Kaierle S, Overmeyer L (2016) Influence of laser power on the shape of single tracks in scanner based laser wire cladding. Phys Procedia 83:667-673. https://doi.org/10.1016/j.phpro.2016.08.069

15. Shi J, Zhu P, Fu G, Shi S (2018) Geometry characteristics modeling and process optimization in coaxial laser inside wire cladding. Opt Laser Technol 101:341-348. https://doi.org/10.1016/j.optlastec.2017.10.035

16. Kottman M, Zhang S, McGuffin-Cawley J, Denney P, Narayanan BK (2015) Laser hot wire process: a novel process for near-net shape fabrication for high-throughput applications. JOM 67: 622-628. 10.1007/s11837-014-1288-1 https://doi.org/10.1007/s11837-014-1288-1

17. Wen P, Feng Z, Zheng S (2015) Formation quality optimization of laser hot wire cladding for repairing martensite precipitation hardening stainless steel. Opt Laser Technol 65:180-188. https://doi.org/10.1016/j.optlastec.2014.07.017

18. Pajukoski H, Näkki J, Thieme S, Tuominen J, Nowotny S, Vuoristo P (2016) High performance corrosion resistant coatings by novel coaxial cold- and hot-wire laser cladding methods. J Laser Appl 28:012011. https://doi.org/10.2351/1.4936988

19. Pater Z (2014) 3.10 - Cross-Wedge Rolling. Comprehensive Materials Processing 3: 211-279. https://doi.org/10.1016/B978-0-08096532-1.00315-0

20. Pater Z, Tomczak J, Bulzak T (2018) New forming possibilities in cross wedge rolling processes. Arch Civ Mech Eng 18(1):149161. https://doi.org/10.1016/j.acme.2017.06.005

21. Kache H, Stonis M, Behrens B-A (2012) Development of a warm cross wedge rolling process using FEA and downsized experimental trials. Prod Eng Res Devel 6:339-348. https://doi.org/10.1007/s11740-012-0379-5

22. Pater Z, Tomczak J, Bulzak T (2018) Analysis of a cross wedge rolling process for producing drive shafts. Int $J$ Adv Manuf Technol 94:3075-3083. https://doi.org/10.1007/s00170-016-9662-5

23. Li Q (2003) Characterization of failure mechanisms in cross wedge rolling. Dissertation, University of Pittsburgh

24. Li Q, Lovell M (2008) Cross wedge rolling failure mechanisms and industrial application. Int J Adv Manuf Technol 37:265-278. https://doi.org/10.1007/s00170-007-0979-y

25. Kruse J, Jagodzinski A, Langner J, Stonis M, Behrens B-A (2020) Investigation of the joining zone displacement of crosswedge rolled serially arranged hybrid parts. Int J Mater Form 13:577-589. https://doi.org/10.1007/s12289-019-01494-3

26. Kruse J, Mildebrath M, Budde L, Coors T, Faqiri MY, Barroi A, Stonis M, Hassel T, Pape F, Lammers M, Hermsdorf J, Kaierle S, Overmeyer L, Poll G (2020) Numerical simulation and experimental validation of the cladding material distribution of hybrid semi-finished products produced by deposition welding and Cross-Wedge rolling. Metals 10(10):1336. https://doi.org/10.3390/met10101336

27. Özel T, Hsu TK, Zeren E (2005) Effects of cutting edge geometry, workpiece hardness, feed rate and cutting speed on surface roughness and forces in finish turning of hardened AISI h13 steel. Int J Adv Manufacturing Technology 25:262-269. https://doi.org/10.1007/s00170-003-1878-5

28. Burhanuddin Y, Che Haron CH, Ghani JA (2011) The effect of tool edge geometry on tool performance and surface integrity in turning Ti-6Al-4V alloys. Adv Mat Res 264:1211-1221. https://doi.org/10.4028/www.scientific.net/AMR.264-265.1211

29. Breidenstein B. (2011) Oberflächen und Randzonen hoch belasteter Bauteile. Habilitation Thesis, Leibniz University Hannover, Hannover, Germany

30. Abrão AM, Denkena B, Breidenstein B, Mörke T (2014) Surface and subsurface alterations induced by deep rolling of hardened AISI 1060 steel. Prod Eng Res Devel 8:551-558. https://doi.org/10.1007/s11740-014-0539-x

31. Oliver M (2017) Lebensdauererhöhung von wälzlagern durch mechanische Bearbeitung Dissertation Gottfried Wilhelm Leibniz universität Hannover

32. Woite M (2021) GmbH. Werkstoff-Nr. 10460. Accessed 22 March. https://woite-edelstahl.info/10460de.html

33. Metal Technology-Canterbro (2019) GmbH. Abnahmeprü,fzeugnis 3.1 nach EN 10204-2005-01 MT-316L 1.4430

34. Matmatch (2021) GmbH. EN 10273 Grade P250GH normalized or normalized formed $(+\mathrm{N})$. Accessed 29 March https://matmatch. com/de/materials/minfm35728-en-10273-grade-p250gh-normaliz ed-or-normalized-formed-n-

35. Deutsche Edelstahlwerke Services (2015) GmbH. Werkstoffdatenblatt X2CrNiMo18-14-3 1.4435. Accessed 22 March 2021. https://www.dew-stahl.com/fileadmin/files/dew-stahl.com/ documents/Publikationen/Werkstoffdatenblaetter/RSH/1.4435_ de.pdf

36. Lammers M, Budde L, Barroi A, Hermsdorf J, Kaierle S (2019) Entwicklung von Laser-Systemkomponenten optimiert für die additive Fertigung mittels SLM. In: Lachmayer R, Lippert $\mathrm{R}$, Kaierle $\mathrm{S}$ (eds) Konstruktion für die additive fertigung, vol 2018. Springer Vieweg, Berlin, Heidelberg, pp 21-35. https://doi.org/10.1007/978-3-662-59058-4_2

37. Macherauch E, Müller P (1961) Das $\sin ^{2} \psi$-verfahren der röntgenographischen Spannungsmessung. Zeitschrift fü,r Angewandte Physik 13(7):305-312

38. Jiang X, Li B, Wang L, Wang Z, Li H (2016) An approach to evaluate the effect of cutting force and temperature on the residual stress generation during milling. Int Journal Adv Manuf Technol 87:2305-2317. https://doi.org/10.1007/s00170-016-8605-5

39. Maiß O (2019) Lebensdauererhöhung von wälzlagern durch mechanische Bearbeitung. Dissertation, Leibniz Universität Hannover

Publisher's note Springer Nature remains neutral with regard to jurisdictional claims in published maps and institutional affiliations. 